\title{
Control Strategies for Microgrids with Distributed Energy Storage Systems: An Overview
}

\author{
Thomas Morstyn, Student Member, IEEE, Branislav Hredzak, Senior Member, IEEE and \\ Vassilios G. Agelidis, Fellow, IEEE
}

\begin{abstract}
This paper presents an overview of the state of the art control strategies specifically designed to coordinate distributed energy storage systems in microgrids. Power networks are undergoing a transition from the traditional model of centralised generation towards a smart decentralised network of renewable sources and energy storage systems, organised into autonomous microgrids. Energy storage systems can provide a range of services, particularly when distributed throughout the power network. The introduction of distributed energy storage represents a fundamental change for power networks, increasing the network control problem dimensionality and adding long time-scale dynamics associated with the storage systems' state of charge levels. Managing microgrids with many small distributed energy storage systems requires new scalable control strategies that are robust to power network and communication network disturbances. The paper reviews the range of services distributed energy storage systems can provide, and the control challenges they introduce. The focus of the paper is a presentation of the latest decentralised, centralised and distributed multi-agent control strategies designed to coordinate distributed microgrid energy storage systems. Finally, multi-agent control with agents satisfying Wooldridge's definition of intelligence is proposed as a promising direction for future research.
\end{abstract}

Index Terms-Centralised control, decentralised control, dynamic optimal power flow, energy management system, energy storage, hierarchical control, microgrid, multi-agent control, smart grid, technology readiness level.

\section{INTRODUCTION}

$\mathbf{P}$ OWER networks are undergoing a transition, from the traditional model of centralised generation, towards a smart decentralised network of distributed renewable sources and energy storage (ES) systems [1]. This transition is being driven by a confluence of trends:

1) The rapid adoption of intermittent renewable sources, particularly photovoltaic (PV) and wind generation [2].

2) Reductions in the cost of ES due to technological developments and increased scales of production [3].

3) The extension of communications and processing infrastructure from the power network transmission level down to the distribution level [4].

This future smart decentralised power network has the potential to reduce pollution and to increase network efficiency

T. Morstyn is with the Department of Engineering Science at The University of Oxford, Oxford OX1 3PJ, United Kingdom. (email: thomas.morstyn@eng.ox.ac.uk)

B. Hredzak is with the School of Electrical Engineering and Telecommunications at The University of New South Wales (UNSW Australia), Sydney, NSW 2052 Australia. (email: b.hredzak@unsw.edu.au)

V. G. Agelidis is with the Department of Electrical Engineering at the Technical University of Denmark, 2800 Kgs. Lyngby, Denmark. (e-mail: (email: vasagel@elektro.dtu.dk)

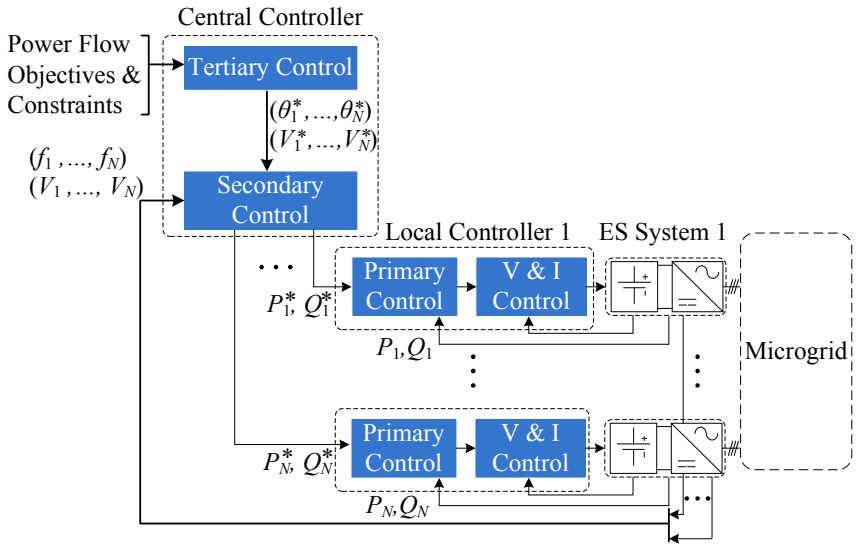

Fig. 1. The traditional hierarchical microgrid control model for an AC microgrid. The central tertiary control solves the microgrid optimal power flow problem and supplies voltage angle and magnitude references to the secondary control. The secondary control generates output power references, implementing the optimal power flow schedule and restoring frequency/voltage offsets introduced by the primary control. At each source, a local primary controller generates references for the lower level power converter voltage/current control to maintain the microgrid power balance.

and reliability. However, intermittent generation and bidirectional power flows introduce challenges for network power quality and stability [5].

The microgrid concept has been proposed as an organising principle for managing information and power flows for networks with distributed sources [6]. A microgrid is a collocated set of generation sources, loads and ES systems, that are coordinated to achieve autonomous operation [7]. Since they can operate autonomously, microgrids can be controlled as dispatchable sources when connected to the main grid, and can continue operation if islanded [8].

The traditional hierarchical microgrid control model has three levels [9], [10], as shown in Fig. 1. The primary control level is responsible for load sharing between the microgrid sources, to maintain stability and autonomous operation (with time-scales on the order of 10 to 100 milliseconds). The most common primary control method is decentralised droop control, which provides load sharing between sources without requiring time-critical communication links [11]. However, droop control introduces a trade-off between load sharing accuracy and microgrid power quality, in the form of voltage/frequency offsets. The centralised secondary control level operates on a slower time-scale (on the order of 1 to 10 seconds), restoring the voltage/frequency offsets introduced by 


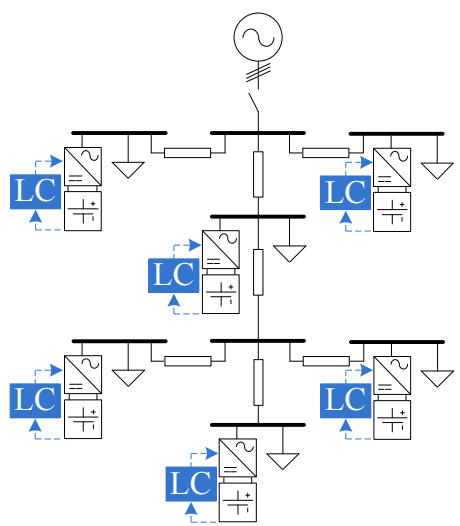

(a) Decentralised

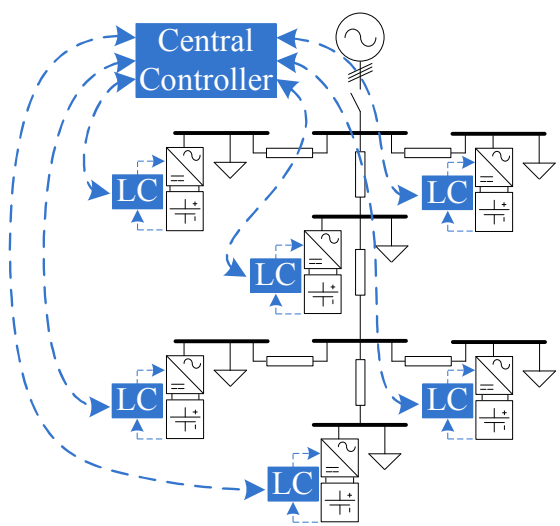

(b) Centralised

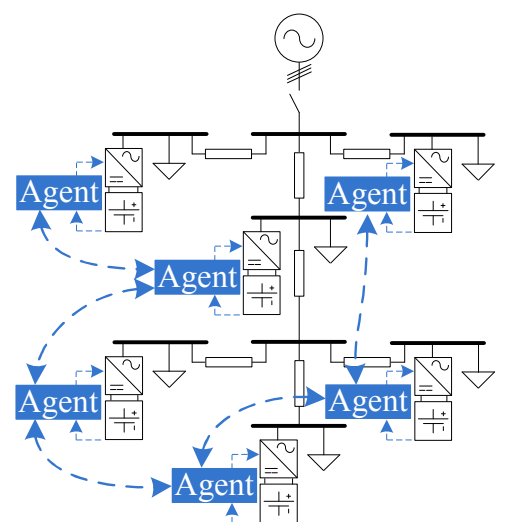

(c) Distributed Multi-Agent

Fig. 2. Control strategy architectures in an AC microgrid with distributed battery energy storage systems. LC: Local Controller.

the primary control. The secondary control level can also be used to correct the primary control load sharing ratios. Finally, the microgrid optimal power flow (OPF) problem is solved on the tertiary control level, calculating optimal references for the microgrid sources based on economic objectives [12]. Constraints on the OPF problem are introduced by the microgrid power quality requirements and device operating limits. The tertiary control level generally operates on a slow time-scale based on a static power flow model (e.g. references updated every 15 minutes). Note that sometimes an equivalent two level microgrid control hierarchy is used instead, with microgrid OPF included as a secondary level control function [13].

The introduction of distributed ES represents a fundamental change for power networks, since the state of charge (SoC) levels of the ES systems must be coordinated over long time-scales. Increasingly, distributed ES systems are being integrated with residential PV systems for energy shifting [14], and with STATCOM at the distribution level for peak shaving and power quality regulation [15]. Distributed ES systems are also used in high-availability applications, such as datacentres [16]. Facebook and Microsoft place batteries at the power distribution unit level of their datacentres, while Google places batteries at each server [17].

The traditional hierarchical microgrid control model does not consider sources with ES capacity. The lack of appropriate control and management strategies has been identified as a limiting factor for integrating distributed ES systems into microgrids [13]. Control strategies for microgrids with distributed ES systems can be broadly divided into three categories, based on their architecture: (a) decentralised, (b) centralised and (c) distributed multi-agent. Fig. 2 shows high-level diagrams of these control strategy architectures for an AC microgrid.

Under a decentralised control strategy, each ES system operates based only on local information. Decentralised control strategies for distributed ES systems have focused on modifications to the primary microgrid droop control, based on the ES systems' SoC levels. However, due to the limited information each ES system has access to, these control strategies are unable to fully utilise the combined power and energy capacities of the ES systems [18].
The centralised secondary control level can be used to adjust the load sharing ratios of the ES systems based on estimates of their SoC levels, efficiencies and/or power capacities. On the tertiary control level, the microgrid dynamic OPF (DOPF) problem can be solved, i.e. the problem of optimally coordinating the output powers of distributed ES systems over a given time horizon. However, the scalability of the DOPF problem is of concern. In general, the DOPF problem is nonconvex, full power network information is required, including renewable generation and load predictions, and the problem dimension increases with each additional ES system [12]. Note that sometimes the term 'energy management system' is used instead of tertiary level DOPF strategy [19]. In this case, the DOPF problem is referred to as the energy management problem.

The processing and communications infrastructure required for a central controller that monitors and independently controls each ES system may be impractical for microgrids with many small ES systems [20]. Also, data centralisation introduces privacy and security concerns [21]. Managing microgrids with many small distributed ES systems requires new scalable control strategies, that are robust to power network and communication network disturbances.

This motivates the use of distributed multi-agent control [22]. Under a distributed multi-agent control strategy, autonomous agents use local information and neighbourto-neighbour communication over a sparse communication network to achieve cooperative objectives [23]. Distributed multi-agent control provides improved performance compared with decentralised control and has advantages in terms of robustness, scalability and flexibility over centralised control. Distributed multi-agent control strategies have been presented for a range of microgrid applications including secondary level voltage/frequency restoration [24]-[27] and tertiary level OPF [28]-[33]. Reviews on multi-agent implementations of the traditional hierarchical microgrid control model are presented in [34]-[36].

Another limitation of the traditional hierarchical microgrid control model is the lack of consideration for sources with competing objectives. Game theory provides a mathematical 
framework for analysing the interactions between competitive agents, and designing market mechanisms to promote cooperative objectives. A review of applications for game theory in microgrid control is presented in [37].

This paper presents an overview of the state of the art control strategies specifically designed to coordinate distributed ES systems in microgrids. Section II reviews the range of services distributed microgrid ES systems can provide, and the control challenges they introduce. Sections III, IV and V present the latest research on decentralised, centralised and distributed multi-agent control strategies designed to coordinate distributed microgrid ES systems. Section VI provides comparative summaries of the control strategies. Section VII proposes multi-agent control for distributed ES systems based on agents satisfying Wooldridge's definition of intelligence [38] as a promising direction for future research. Section VIII concludes the paper.

\section{Distributed Microgrid Energy Storage}

ES systems can provide a range of services, particularly when distributed throughout the power network (e.g. at the distribution level, collocated with loads) [39]. ES system services can be broadly grouped into four categories:

1) Energy Shifting: Energy generated during periods of excess supply can be stored and shifted to periods of high demand. This can add significant value to intermittent renewable sources.

2) Peak Shaving: Short-term load spikes can be supplied by local ES systems, reducing the peak demand seen at higher levels in the power network hierarchy. This lowers the required capacity of generation/transmission infrastructure and avoids peak power fees.

3) Power Quality Regulation: ES systems can be used to address network power quality issues such as voltage/frequency offsets, harmonics, voltage unbalance and low power factor.

4) Spinning Reserve: ES systems can provide backup power in case of islanding, increasing availability.

Making effective use of ES systems is critical, due to their relatively high cost of energy provisioned compared to conventional generation sources, once charge/discharge losses and depreciation due to lifetime degradation are taken into account [40]. ES technologies have different characteristics, making them suitable for particular services. Relevant characteristics include charging/discharging efficiency, specific energy $(\mathrm{kWh} / \mathrm{kg})$, specific power $(\mathrm{kW} / \mathrm{kg})$, energy capacity cost $(\$ / \mathrm{kWh})$, power capacity cost $(\$ / \mathrm{kW})$, cycle life and selfdischarge rate [41].

The control strategy used to coordinate distributed microgrid ES systems determines the services they provide, their lifetime and efficiency. For example, electrochemical battery technologies (e.g. lead-acid, lithium ion) that are discharged to low SoC will suffer greater lifetime degradation [42]. Also, battery efficiency is reduced at high charge/discharge rates and at lower SoC levels [43]. The placement of the ES systems in the microgrid, relative to loads, also impacts on round trip efficiency. This means that the control strategy has a direct impact on the economic viability of the ES systems, and their optimal placement and sizing.

\section{Decentralised Control Strategies}

To achieve autonomous operation, the microgrid power balance must be maintained at all times. Within the traditional hierarchical microgrid control model, the primary control level is responsible for this. The standard primary control strategy is decentralised droop control, which provides load sharing between sources interfaced with the microgrid through power electronic converters, without time-critical communication links. Alternatively, a centralised active load sharing strategy can be used, but generally this is only practical for closely located sources, due to the high bandwidth control loops required [44].

\section{A. Traditional Droop Control}

For AC microgrids with mainly reactive impedance, the real power flows are dependent on the bus voltage angles, while the reactive power flows are dependent on the bus voltage magnitudes. This motivates the traditional $f-P$, $V-Q$ droop control. The converters reduce their frequency in proportion to their real output power, and their output voltage in proportion to their reactive output power. This means that, in steady-state, they share the real and reactive load in inverse proportion to their droop coefficients. Low voltage microgrids often have mainly resistive lines, in which case $V-P, f-Q$ droop control can be used. Also, virtual impedance can be introduced to reduce the coupling between real and reactive power flows [45]. For DC microgrids, $V-I$ droop control is commonly used. The droop coefficients are selected so that the sources share the microgrid load in proportion to their power capacities, within the allowed voltage/frequency limits of the microgrid.

The standard droop control is unsuitable for distributed ES systems, since it does not take their SoC levels into account. Under a power capacity proportional load sharing strategy, ES systems which begin with lower SoC are expected to prematurely run out of energy. This is undesirable, since ES systems which have run out of energy cannot contribute their power capacity to the microgrid. For battery ES systems in particular, operation at low SoC results in additional lifetime degradation and low efficiency [43]. Even when the load is accurately shared between ES systems with the same SoC, their SoC levels are expected to diverge, since differences such as manufacturing tolerances, remaining lifetime and temperature will affect the ES systems' charge/discharge efficiencies. Also, in low voltage $\mathrm{AC}$ microgrids operating under $V-P$ droop control, and in DC microgrids operating under $V-I$ droop control, line voltage drops prevent exact load sharing.

\section{B. State of Charge Weighted Droop Control}

Decentralised SoC weighted droop control can be used to ensure that none of the distributed ES systems prematurely run out of energy [46]. ES systems with lower SoC increase their droop coefficients, so that they provide a relatively smaller 
share of the microgrid load. The ES systems' SoC levels will converge as they all approach the maximum or minimum SoC level. The rate of SoC balancing can be controlled by applying an exponent to the value used to weight the ES system droop coefficient [47], [48]. An alternative method is for the ES systems to adjust the nominal microgrid voltage/frequency based on their SoC levels [49], [50]. This has the advantage of making the average ES system $\mathrm{SoC}$ observable from the microgrid voltage/frequency offset.

SoC weighted droop control has two main limitations. First, since ES systems with lower SoC do not use their full power capacities, ES systems with high SoC may be overloaded during high load conditions. Second, as all of the ES systems reach a low SoC level, all of their droop coefficients are increased, and voltage/frequency regulation in the microgrid suffers. In [51], [52], fuzzy inference is used for a DC microgrid so that the ES systems' droop coefficients depend on their SoC levels and output voltages. This reduces the impact on voltage regulation when all of the ES systems have low SoC.

The voltage/frequency offsets of a droop based control strategy can be used to coordinate the operating modes of the distributed battery ES systems. In [53], DC microgrid voltage thresholds are used to coordinate transitions between the power balance being maintained by the batteries during normal operation, by renewable sources when the batteries are full (using generation curtailment) and by the main grid if the batteries are empty and there is insufficient renewable generation to feed the load. A similar scheme is presented for AC microgrids in [54]. Fuzzy inference can used to smooth the microgrid mode transitions [55], [56]. In [57], high frequency power line signalling is used to coordinate mode transitions between DC microgrid battery ES systems. This increases the maximum number of modes compared to methods relying on steady-state voltage offset thresholds.

During grid connected operation, ES systems collocated with intermittent renewable sources can be operated for peak shaving to minimise the net power imported/exported [58]. This can be used to limit voltage fluctuations in feeders with distributed renewable generation.

\section{Droop Control for Heterogeneous Energy Storage Systems}

ES technologies can be broadly divided into those suitable for peak shaving and power quality regulation, versus those suitable for energy shifting and spinning reserve. For example, ultracapacitors have relatively low power cost $(\$ / \mathrm{kW})$, high specific power $(\mathrm{kW} / \mathrm{kg})$ and high cycle life, making them suitable for balancing high frequency load fluctuations required to maintain the microgrid power quality. However, their high energy cost $(\$ / \mathrm{kWh})$ and low specific energy $(\mathrm{kWh} / \mathrm{kg})$ make them unsuitable for supplying the low frequency bulk energy requirement of the microgrid.

A range of control strategies for individual hybrid ES systems (ES systems combining multiple storage technologies) have been proposed [59]. The control strategy in [60] considers a DC microgrid with distributed ultracapacitors and lead-acid batteries. High-pass droop control is introduced for the ultracapacitors, so that they supply the high frequency load, while the lead-acid batteries operate under the traditional droop control and supply the low frequency load. Each ultracapacitor has an additional slow PI control loop to restore its voltage to a desired reference, preventing it from running out of energy.

\section{Centralised Control Strategies}

A centralised control strategy can be used to individually monitor and control microgrid ES systems. The technical literature on centralised microgrid control strategies can be divided between the secondary and tertiary control levels. Control strategies with transient control objectives, such as power quality regulation, are described as secondary, while DOPF strategies based on renewable generation and load predictions are described as tertiary.

\section{A. Centralised Secondary Control}

Under the traditional hierarchical microgrid control model, the centralised secondary control level is introduced to improve power quality by correcting voltage/frequency offsets introduced by the primary droop control [9]. Secondary level control strategies have also been proposed for voltage unbalance correction [61], harmonic compensation and to improve reactive power sharing [62].

This section presents secondary level control strategies specifically designed to coordinate microgrid ES systems. By taking into account the ES systems' SoC levels and operating characteristics, a range of different control objectives are achieved, which are not possible with a decentralised control strategy.

In [63], the standard centralised secondary control for voltage/frequency restoration is added to the $\mathrm{SoC}$ weighted droop control to regulate the microgrid power quality when the ES systems reach low SoC. However, there is still the potential for high SoC ES systems to be overloaded during high load conditions.

A centralised control strategy for discharge rate balancing between distributed AC microgrid ES systems is presented in [64]. As long as the ES systems begin at the same SoC, they will remain balanced, and none will prematurely run out of energy or become overloaded. The strategy presented in [65] allocates the microgrid load between ES systems to minimise costs associated with battery depreciation, considering the impact of the SoC level and charge/discharge rate on battery lifetime.

In [66], a centralised secondary control strategy is introduced for a DC microgrid with distributed lead-acid battery ES systems coordinated by SoC weighted primary droop control. The centralised secondary control imposes roundrobin constant voltage charging once the batteries reach a float voltage, to minimise the number of charge/discharge cycles and improve battery lifetime.

SoC balancing has been proposed as a means of fully utilising the combined power and energy capacities of distributed microgrid ES systems. Under a SoC balancing control strategy, the microgrid ES systems share the load, while using their excess power capacities to move towards a balanced SoC. Once a balanced $\mathrm{SoC}$ is achieved, the combined power and energy 
capacities of the microgrid ES systems are available to balance generation/load fluctuations in the microgrid, improving power quality regulation and increasing the spinning reserve of the microgrid. SoC balancing is particularly desirable for battery ES systems, since the maximum depth of discharge is reduced, increasing efficiency and battery lifetime. Centralised secondary level control strategies for SoC balancing between microgrid ES systems are presented in [67]-[70].

Rule-based control can be introduced to coordinate ES system operating modes [71]. In [72], [73], rule-based control strategies are presented to coordinate vanadium redox flow batteries and ultracapacitors collocated with a PV generation plant. In [74], a rule-based control strategy is presented that uses multi-agent system design to organise information flows between distributed ES systems. This strategy includes a central control agent, so it is not classified as a distributed multi-agent control strategy.

\section{B. Centralised AC Microgrid Tertiary Control}

The power network OPF problem attempts to find an optimal solution for distributed generation sources with constraints introduced by network power quality requirements and device operating limits [75]. The general AC microgrid OPF problem is non-convex, due to the nonlinear relationship bus voltage magnitudes and angles have with the real and reactive power flows. This non-convexity makes the OPF problem computationally challenging and the solution methods available are either approximate or heuristic, and not guaranteed to find a globally optimal solution [76].

The complexity of the OPF problem is one of the motivations behind the microgrid concept, which collects generation sources, loads and ES systems into dispatchable units, simplifying the higher level power network optimisation. Within a microgrid, the traditional hierarchical control model assigns the OPF problem to the tertiary control level, which generates references for the lower level primary and secondary control. When a grid connection is available, the OPF problem can be used to optimise the power flows between the microgrid and the main grid (with objectives such as profit maximisation or the provision of ancillary services). When islanded, a natural objective is to minimise power consumption in the microgrid while making full use of the available renewable generation.

To optimise the use of distributed ES systems, the DOPF problem is introduced, which finds the optimal energy flows between the ES systems over a time horizon, during which predictions of the microgrid load and renewable generation are available. The selection of the optimisation objective function and constraints determines the services provided by the ES systems. For example, if profit maximisation is chosen as an objective, the ES systems shift energy so that power is exported to the main grid when the price of energy is predicted to be high. If constraints are imposed on the power imported from the main grid, the ES systems will be used for peak shaving. Constraints on the ES system SoC levels prevent overcharging/undercharging, and can be used to ensure additional energy is available as spinning reserve, in case the microgrid becomes islanded.

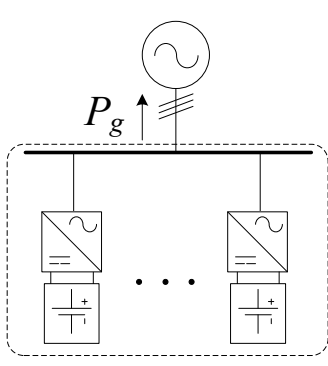

(a) Single/aggregated ES system.

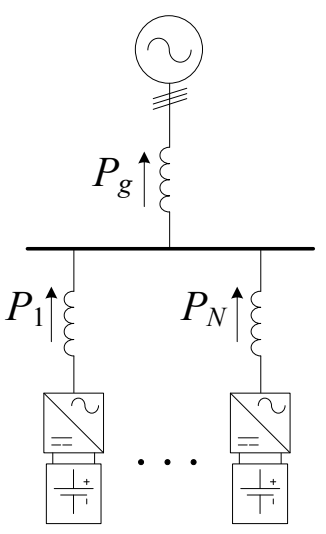

(c) Convex approximation (e.g. DC power flow).

Fig. 3. Dynamic optimal power flow power network models

Tertiary level control of distributed microgrid ES systems can be implemented using receding horizon model predictive control (MPC) [77]. During each sampling interval, the DOPF problem is solved based on up to date SoC estimates and predictions of the renewable generation and load. The power references generated for the first interval of the time horizon are sent to the lower level control and the time horizon recedes by a step for the next sampling interval.

Microgrid DOPF strategies can broadly be divided into four categories, based on the approximations used to simplify the problem: (a) single/aggregated ES system, (b) ideal real power transfer, (c) convex approximation or (d) non-convex optimisation. Power network models fitting these categories are shown in Fig. 3.

(a) The first group of DOPF strategies are designed for microgrids with a single ES system, or microgrids with aggregated ES capacity [78]-[83]. Power flows between the microgrid and the main grid can be optimised, but power flows between the ES systems are not considered. The DOPF strategy presented in [83] includes the cost of battery depreciation through a weighted Ah throughput model for lead-acid battery lifetime degradation.

(b) The second group of DOPF strategies are based on an ideal real power transfer model between the ES systems [84], [85]. An equivalent assumption is that all of the ES systems are connected to a common bus [86]. In these cases, the microgrid power balance requirement simplifies to a linear equality constraint, yielding a convex optimisation problem. These strategies allow the relative SoC of distributed ES 
systems to be considered, but the network topology is not taken into account. In [87], stochastic dynamic programming is used to consider prediction uncertainty, as well as nonlinear models for battery depreciation costs and charging/discharging efficiency. Particle swarm optimisation is used in [88], [89] to solve the DOPF problem for a microgrid with both battery ES systems and thermal ES in the form of combined cooling, heating and power units.

(c) The third group of DOPF strategies use convex approximations of the DOPF problem, since fast and robust solvers are readily available for convex optimisation problems [90]. In networks with high $\mathrm{X} / \mathrm{R}$ ratios, the $\mathrm{DC}$ power flow approximation can be used [91], [92]. The DC power flow approximation assumes the line impedances are purely reactive and the bus voltage angle differences are small. In this case, the microgrid real power flows depend linearly on the bus voltage angles. Line losses, bus voltage limits and reactive power flows are not considered by the optimisation. The DOPF strategy in [93] uses the convex OPF problem relaxation from [76], which is exact under certain conditions and can be solved using semidefinite programming. In [94], a branch flow method is presented for convex relaxation of the OPF problem.

(d) Finally, the fourth group consists of strategies that use a power network model that gives a non-convex optimisation problem. In [95], mixed integer linear programming and nonlinear programming are combined to solve the DOPF problem for a microgrid with distributed ES systems, accounting for on/off decisions for distributed generation sources. Nonlinear programming also allows unbalanced phases to be considered. This approach was extended in [96] with stochastic optimisation to provide probabilistic feasibility guarantees. An alternative approach is to use recursive dynamic programming [12]. The range of SoC values allowed for each ES system is quantised using a suitable step size, and backward recursion is used to calculate the differential cost plus the minimum cost-to-go for all possible SoC transitions (i.e. energy flows) over the optimisation time horizon that satisfy the power network constraints. The optimal set of energy flows are then found using forward recursion. A globally optimal solution is obtained, but the problem dimension increases with each additional ES system, limiting scalability.

\section{Centralised DC Microgrid Tertiary Control}

DOPF strategies have also been developed for DC microgrids. Power flow optimisation is particularly important for high voltage multi-terminal DC distribution used to connect large offshore wind farms to the main grid [97]. Although reactive power and bus voltage angles do not need to be considered, the DC microgrid DOPF problem is still nonconvex, due to the quadratic relationship between the bus voltages and the microgrid power flows.

DOPF strategies for DC microgrids can be divided into the same four categories as the AC microgrid DOPF strategies.

(a) DOPF strategies for microgrids with a single ES system are presented in [98]-[100].

(b) DOPF strategies for DC microgrids with multiple ES systems connected at a common DC bus are presented in [101], [102]. (c) \& (d) In [103], the DC microgrid DOPF problem is formulated as a non-convex quadratically constrained quadratic program and a convex relaxation is presented which can be solved using second-order cone programming. In [104], a DC microgrid MPC strategy is presented based on a convex quadratic programming formulation of the DOPF problem, obtained from linear power flow approximations.

\section{Distributed Multi-Agent Control Strategies}

The decentralised control strategies described in Section III provide a scalable solution for coordinating many small distributed microgrid ES systems, since they require only local information. However, they are unable to fully utilise the combined power and energy capacities of the ES systems. This can be achieved with the centralised control strategies in Section IV, but the processing and communication infrastructure required limits scalability [20], and data centralisation introduces privacy and security concerns [21]. Distributed multi-agent control provides an alternative to these two extremes. Distributed multi-agent control is a developing area of control systems research, which considers systems controlled by autonomous agents connected by a sparse communication network [23].

Distributed multi-agent control strategies have been proposed for both the secondary and tertiary control levels of microgrids with distributed ES systems.

On the secondary level, each ES system acts as an autonomous agent, sharing information with neighbouring ES systems (e.g. SoC level, output power) to coordinate load sharing and achieve cooperative objectives.

On the tertiary level, distributed multi-agent implementations of the DOPF problem allow cooperative autonomous agents with limited power network information to agree on a set of optimal microgrid energy flows by iteratively solving limited size sub-problems in parallel and sharing their results with their neighbours.

An alternative to a cooperative tertiary level strategy for DOPF is a competitive tertiary level strategy. Under a competitive strategy, autonomous agents attempt to maximise their local utility, based on price information. Market mechanisms can be used to promote cooperative objectives, such as maintaining the microgrid power balance.

\section{A. Distributed Multi-Agent Secondary Control}

The distributed multi-agent secondary level control strategies reviewed in this section draw on the theoretical framework of cooperative consensus problems for networked dynamic systems [105], [106]. Within this framework, the distributed microgrid ES systems are modelled as dynamic systems, sparsely interconnected by the microgrid power lines and communication network information links. Distributed multiagent control design considers how information should be exchanged and used by the agents so that they reach agreement regarding quantities that depend on their collective states (e.g. average consensus, leader-tracking) [107]. An extensive literature has been developed for this, including methods for scalable optimal controller/observer design [108], robustness 


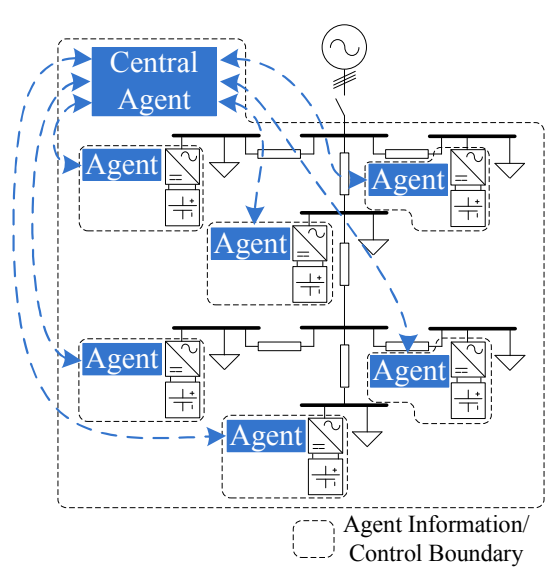

(a) Hierarchical

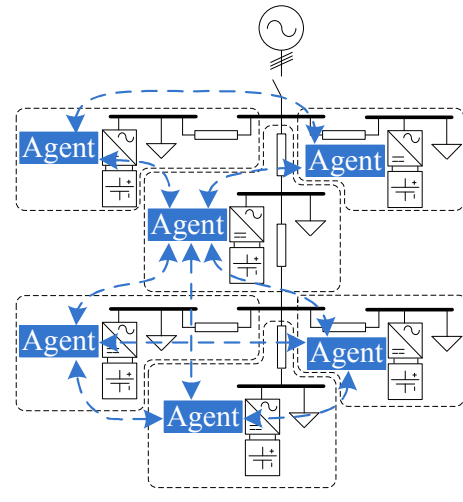

(b) Topology Based Message Passing

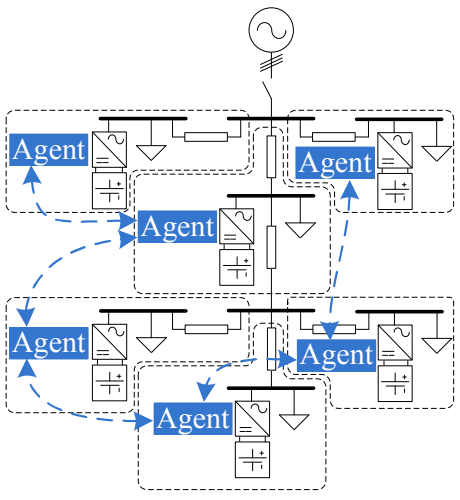

(c) Fully Distributed

Fig. 4. Distributed multi-agent dynamic optimal power flow communication architectures in an AC microgrid with distributed battery energy storage systems.

to communication network delays and topology changes [109] and an internal model principle for zero steady-state error reference tracking [110].

Distributed multi-agent control strategies for SoC balancing between distributed microgrid ES systems have been presented for AC microgrids [18], [111], [112] and DC microgrids [113]-[116]. Based on local SoC information and neighbourto-neighbour communication, the distributed ES systems use their excess power capacities to move towards a balanced SoC. The lower level primary droop control ensures the microgrid power balance is maintained in case of communication failures. Once a balanced $\mathrm{SoC}$ is reached, it is maintained through accurate load sharing, naturally correcting for the error normally introduced by the droop control. Since voltage/frequency offsets are no longer required for accurate steady-state load sharing, distributed controllers for voltage/frequency restoration can be introduced [18], [115]. Distributed multi-agent SoC balancing with robustness to communication delays is presented in [112].

Distributed multi-agent control strategies can coordinate ES systems for different microgrid operating modes. In [117], a multi-agent rule-based control strategy is presented to coordinate ES systems agents which can be charging, discharging or providing voltage regulation and circuit breaker agents which can be on or off, to maintain continuity of supply to microgrid segments. The team of agents associated with a segment are completely connected, but inter-team communication is sparse. In [115], a unified distributed multi-agent control strategy for the different operating modes of a DC microgrid (operation as a grid connected source, grid connected load and islanded) is presented. This removes the need for bus voltage signalling and mode detection mechanisms.

The DC microgrid multi-agent control strategy in [116] provides coordination between distributed ultracapacitor ES systems, used for peak shaving and power quality regulation, and battery ES systems, which supply the low frequency microgrid load during islanded operation. The control strategy is based on two interconnected leader-tracking SoC consensus networks, one between the ultracapacitor ES systems and the other between the battery ES systems.
An alternative objective for multi-agent secondary control of distributed microgrid ES systems is efficiency maximisation. Under the control strategy presented in [118], distributed ES systems cooperatively adjust their output powers based on an equal incremental cost criterion to minimise charge/discharge losses while remaining within their SoC limits and maintaining the microgrid power balance.

\section{B. Cooperative Multi-Agent Tertiary Control}

Distributed MPC provides a scalable means of implementing DOPF between distributed microgrid ES systems. A review of distributed MPC approaches is given in [119]. The approaches are divided based on the type of control they provide: regulation, tracking or economic optimisation. The ones that provide economic optimisation are of interest for microgrid DOPF. Within this group, the approaches vary in terms of the communication architecture between the agents and the information required by each agent. Distributed OPF methods that do not consider ES systems are presented in [28]-[33].

Distributed multi-agent DOPF strategies can be separated, according to their communication architecture, into three categories: (a) hierarchical, (b) topology based message passing and (c) fully distributed. Within these categories, the strategies are based on different approximations of the DOPF problem, since distributed optimisation methods are mainly designed to solve convex optimisation problems. Fig. 4 shows examples of these architectures for an AC microgrid.

(a) Hierarchical multi-agent DOPF strategies are presented in [120]-[122]. In [120], the microgrid DOPF problem is iteratively solved by a central agent and autonomous distributed agents, each associated with a distributed generation source, ES system or controllable load. The central agent has information on the power network topology, while each distributed agent has access to its local device's objective function and operating constraints. The central agent and distributed agents solve parallel convex optimisation problems, and converge to a solution based on price variables that are iteratively updated. A similar approach is presented in [121] with an ideal power transfer model between the ES systems. The DOPF strategy presented in [122] has two tertiary control 
levels. A central agent solves the DOPF problems for a group of interconnected microgrids, considering each microgrid as a single dispatchable source with ES capacity. Lower level microgrid agents then solve separate DOPF problems for their local ES systems, with the goal of minimising losses while meeting the power references scheduled by the higher level central agent. Although the hierarchical multi-agent tertiary level strategies require centralised communication, they are distinguished from the centralised tertiary level strategies from Section IV-B, since the processing infrastructure and power network information is distributed between autonomous agents.

(b) Multi-agent DOPF strategies using topology based message passing are presented in [123]-[125]. These control strategies introduce agents and a communication network between them that mirrors the underlying power network topology. The control strategy in [123] uses the DC power flow approximation to obtain a convex DOPF problem. The convex problem is divided between agents, each associated with a power network component (e.g. transmission line, generation source, ES system, load). The DOPF problem is iteratively solved using alternating direction method of multipliers (ADMM). Each iteration, distributed agents associated with individual power network components solve local optimisation problems. The component agents are connected by net agents. The net agents update residual variables that indicate the distance from convergence, which are used during the next iteration. The DOPF strategy in [124] is based on dual decomposition, and a different convex OPF approximation that assumes all of microgrid lines have the same $\mathrm{X} / \mathrm{R}$ ratio. Agents are introduced for each generation source and ES system, and the communication network between them matches the power network topology. In [125], topology based message passing DOPF is presented for interconnected microgrids. Each microgrid is modelled as a controllable source with ES capacity, which can trade energy with neighbouring microgrids.

(c) The DOPF strategies presented in [126], [127] are fully distributed, in the sense that any communication network topology is acceptable, as long as a path is provided between all of the agents. The DOPF strategy in [126] is based on an ideal power transfer model between the ES systems, so the power network topology is not considered. In [127] a convex formulation of the AC microgrid DOPF problem is developed from a d-q reference frame voltage-current model and linear power flow approximations. This allows line losses and voltage constraints to be explicitly considered. A fully distributed communication architecture provides increased robustness and flexibility compared with the hierarchical and topology based message passing communication architectures, since there is no central control agent and the communication/control layer is decoupled from the power network topology.

\section{Competitive Multi-Agent Tertiary Control}

Tertiary level microgrid DOPF is relevant for coordinating cooperative agents with ES systems to achieve collective goals, such as minimising power consumption. However, microgrids may also have competitive agents with ES systems. In this case, each agent has its own objectives (e.g. supplying local loads, maximising profit from selling energy).

A market based tertiary level control strategy can be used to coordinate competitive microgrid ES systems. Market based tertiary level strategies for microgrids with distributed ES systems are presented in [128]-[130]. These control strategies can be categorised as having a hierarchical distributed multiagent communication architecture, shown in Fig. 4(a), since they include distributed autonomous agents, which communicate with a central market agent. In [128], two market types are considered, single-price auction and pay-as-bid auction. Bidding strategies are analysed for a microgrid with two agents. In [129], a reverse auction approach is presented, allowing different sources to compete to supply loads on an hour ahead basis. It is assumed that ES systems with higher SoC levels are willing to provide energy at lower prices. In [130], a power network is considered with multiple microgrid agents (controlling generation sources) and consumer agents (with local ES systems). The microgrid agents form coalitions and set an energy price to maximise their profit. Then, each consumer agent decides how much energy to buy, considering the price of energy, their local load, ES system SoC and predictions of the other agents' loads.

Cooperative and competitive tertiary level control strategies may operate together in the future smart decentralised grid. For example, a market based tertiary level strategy may be introduced to allow energy trading between households with renewable generation and ES systems in a distribution network. Rather than operating as individuals in the market, households on the same feeder may decide to form a cooperative microgrid, and use a tertiary level DOPF strategy so that they operate together to share risk and increase their collective utility.

\section{Comparative Summaries}

Table I presents a comparative summary of the primary level control strategies from Section III and secondary level control strategies from sections IV and V. The control strategies are compared based on the following criteria:

1) Control Architecture: (D) Decentralised, (C) centralised or (M) distributed multi-agent.

2) Microgrid Type: (AC) or (DC).

3) Voltage/Frequency Regulation: $(\checkmark)$ Zero steady-state error, (F) offsets partially corrected using fuzzy inference or $(\times)$ not corrected.

4) Combined Power Capacity Fully Utilised: $(\checkmark)$ or $(\times)$.

5) Combined Energy Capacity Fully Utilised: $(\checkmark)$ or $(\times)$.

6) Islanded Mode: $(\checkmark)$ or $(\times)$.

7) Grid Connected Mode: $(\checkmark)$ or $(\times)$.

8) Dedicated ES Charge Mode: $(\checkmark)$ or $(\times)$.

9) Local ES used for Peak Shaving: $(\checkmark)$ or $(\times)$.

10) High Frequency Load Assigned to Ultracapacitors: $(\checkmark)$ or $(\times)$.

11) ES Cycle Life Optimised: $(\checkmark)$ or $(\times)$.

12) ES Efficiency Optimised: $(\checkmark)$ or $(\times)$.

13) Robust to Communication Delays: $(\checkmark)$ Yes, $(\times)$ no or $(-)$ not applicable. 
TABLE I

COMPARATIVE SUMMARY:

Primary and SeCondary LeVel Control StRategies

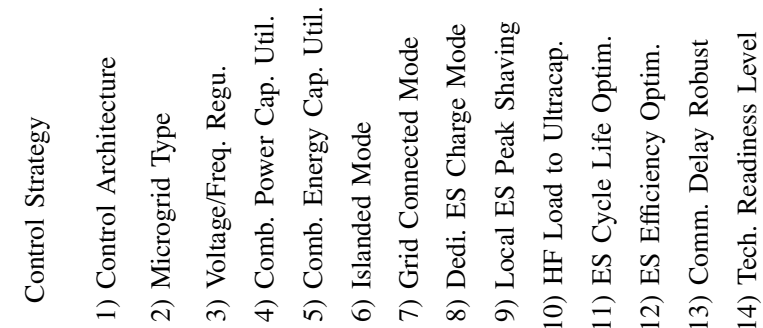

\begin{tabular}{|c|c|c|c|c|c|c|c|c|c|c|c|c|c|c|}
\hline [46] & D & AC & $\times$ & $\times$ & $\checkmark$ & $\checkmark$ & $\times$ & $x$ & $\times$ & $x$ & $x$ & $x$ & - & \\
\hline [47] & D & DC & $x$ & $x$ & $\checkmark$ & $\checkmark$ & $x$ & $\times$ & $x$ & $x$ & $x$ & $x$ & - & \\
\hline [48] & D & DC & $\times$ & $\times$ & $\checkmark$ & $\checkmark$ & $x$ & $\times$ & $\times$ & $x$ & $x$ & $\times$ & - & 4 \\
\hline [49] & D & DC & $\times$ & $x$ & $\checkmark$ & $\checkmark$ & $\checkmark$ & $\times$ & $\times$ & $x$ & $x$ & $\times$ & - & 3 \\
\hline [50] & D & DC & $x$ & $\times$ & $\checkmark$ & $\checkmark$ & $x$ & $x$ & $\times$ & $x$ & $x$ & $x$ & & 4 \\
\hline [51] & D & DC & $\mathrm{F}$ & $\times$ & $\checkmark$ & $\checkmark$ & $x$ & $\checkmark$ & $\times$ & $x$ & $x$ & $x$ & - & 4 \\
\hline [52] & D & DC & F & $\times$ & $\checkmark$ & $\checkmark$ & $x$ & $\checkmark$ & $x$ & $x$ & $x$ & $\times$ & - & 4 \\
\hline [53] & D & DC & $x$ & $\times$ & $\times$ & $\checkmark$ & $\checkmark$ & $\checkmark$ & $\times$ & $x$ & $x$ & $x$ & - & 4 \\
\hline [54] & D & $\mathrm{AC}$ & $\times$ & $x$ & $x$ & $\checkmark$ & $x$ & $\checkmark$ & $x$ & $x$ & $x$ & $x$ & - & 4 \\
\hline [55] & D & AC & $x$ & $\times$ & $\checkmark$ & $\checkmark$ & $x$ & $\checkmark$ & $\times$ & $x$ & $x$ & $x$ & - & 4 \\
\hline [56] & D & AC & $x$ & $x$ & $\checkmark$ & $\checkmark$ & $x$ & $\checkmark$ & $x$ & $x$ & $x$ & $x$ & - & 4 \\
\hline [57] & D & DC & $\times$ & $x$ & $\times$ & $\checkmark$ & $x$ & $\checkmark$ & $\times$ & $\times$ & $x$ & $\times$ & - & 4 \\
\hline [58] & D & AC & $x$ & $x$ & $x$ & $x$ & $\checkmark$ & $\times$ & $\checkmark$ & $x$ & $x$ & $x$ & - & 5 \\
\hline [60] & D & DC & $x$ & $x$ & $x$ & $\checkmark$ & $\checkmark$ & $\checkmark$ & $\times$ & $\checkmark$ & $x$ & $x$ & - & 4 \\
\hline [63] & $\mathrm{C}$ & $\mathrm{AC}$ & $\checkmark$ & $x$ & $\checkmark$ & $\checkmark$ & $x$ & $x$ & $x$ & $x$ & $x$ & $x$ & $x$ & 4 \\
\hline [64] & C & AC & $\checkmark$ & $\checkmark$ & $\checkmark$ & $\checkmark$ & $x$ & $\times$ & $x$ & $x$ & $x$ & $x$ & $x$ & 4 \\
\hline [65] & C & AC & $x$ & $x$ & $x$ & $x$ & $\checkmark$ & $x$ & $x$ & $x$ & $\checkmark$ & $x$ & $x$ & 3 \\
\hline [66] & $\mathrm{C}$ & DC & $x$ & $x$ & $\checkmark$ & $\checkmark$ & $x$ & $\checkmark$ & $x$ & $x$ & $x$ & $x$ & $x$ & 4 \\
\hline [67] & C & DC & $x$ & $\checkmark$ & $\checkmark$ & $\checkmark$ & $\times$ & $\times$ & $\times$ & $\times$ & $x$ & $x$ & $x$ & 4 \\
\hline [68] & $\mathrm{C}$ & DC & $x$ & $\checkmark$ & $\checkmark$ & $\checkmark$ & $x$ & $x$ & $x$ & $\checkmark$ & $x$ & $x$ & $x$ & 4 \\
\hline [69] & C & AC & $\checkmark$ & $\checkmark$ & $\checkmark$ & $\checkmark$ & $x$ & $x$ & $x$ & $x$ & $x$ & $x$ & $x$ & 4 \\
\hline [70] & $\mathrm{C}$ & AC & $\checkmark$ & $\checkmark$ & $\checkmark$ & $\checkmark$ & $x$ & $x$ & $x$ & $x$ & $x$ & $x$ & $x$ & 4 \\
\hline [72] & C & DC & $x$ & $x$ & $x$ & $x$ & $\checkmark$ & $\checkmark$ & $x$ & $\checkmark$ & $x$ & $x$ & $x$ & 5 \\
\hline [73] & C & AC & $x$ & $x$ & $x$ & $x$ & $\checkmark$ & $\checkmark$ & $x$ & $\checkmark$ & $x$ & $x$ & $x$ & 5 \\
\hline [74] & C & AC & $x$ & $x$ & $x$ & $\checkmark$ & $x$ & $\checkmark$ & $x$ & $x$ & $x$ & $x$ & $x$ & 2 \\
\hline [18] & M & AC & $\checkmark$ & $\checkmark$ & $\checkmark$ & $\checkmark$ & $x$ & $x$ & $\times$ & $x$ & $x$ & $x$ & $x$ & 4 \\
\hline [111] & M & $\mathrm{AC}$ & $x$ & $\checkmark$ & $\checkmark$ & $\checkmark$ & $x$ & $\times$ & $x$ & $x$ & $x$ & $x$ & $x$ & 4 \\
\hline [112] & M & $\mathrm{AC}$ & $\times$ & $\checkmark$ & $\checkmark$ & $\checkmark$ & $x$ & $x$ & $x$ & $x$ & $x$ & $\times$ & $\checkmark$ & 5 \\
\hline [113] & M & DC & $x$ & $\checkmark$ & $\checkmark$ & $\checkmark$ & $x$ & $\times$ & $x$ & $x$ & $x$ & $x$ & $x$ & 4 \\
\hline 114] & M & DC & $x$ & $\checkmark$ & $\checkmark$ & $\checkmark$ & $x$ & $x$ & $x$ & $x$ & $x$ & $x$ & $x$ & 4 \\
\hline [115] & M & DC & $\checkmark$ & $\checkmark$ & $\checkmark$ & $\checkmark$ & $\checkmark$ & $\checkmark$ & $\times$ & $\times$ & $x$ & $\times$ & $\times$ & 5 \\
\hline [116] & M & DC & $\checkmark$ & $\checkmark$ & $\checkmark$ & $\checkmark$ & $\checkmark$ & $x$ & $\checkmark$ & $\checkmark$ & $x$ & $x$ & $x$ & 5 \\
\hline [117] & M & AC & $\checkmark$ & $x$ & $x$ & $\checkmark$ & $\checkmark$ & $\checkmark$ & $x$ & $x$ & $x$ & $x$ & $x$ & 5 \\
\hline [118] & M & $\mathrm{AC}$ & $x$ & $x$ & $x$ & $\checkmark$ & $\checkmark$ & $\times$ & $x$ & $x$ & $x$ & $\checkmark$ & $x$ & 5 \\
\hline
\end{tabular}

14) Technology Readiness Level: (1) - (9).

Table II presents a comparative summary of the tertiary level DOPF strategies from sections IV and V. The control strategies are compared based on the following criteria:

1) Control Architecture: (C) Centralised, or distributed multi-agent: (MH) hierarchical, (MT) topology based message passing or (MF) fully distributed.

2) Microgrid Type: (AC), (DC) or (Hyb) hybrid AC/DC.

3) Power Network Model: (S) Single/aggregated ES system, (I) ideal real power transfer, (C) convex approximation or (N) non-convex optimisation.

4) ES SoC Model: (NL) Nonlinear (e.g. SoC and/or output power dependent efficiency), (PL) piece-wise linear (i.e. fixed charging and discharging efficiency) or (L) linear
TABLE II

COMPARATIVE SUMMARY:

Tertiary Level Dynamic Optimal Power Flow Strategies

\begin{tabular}{|c|c|c|c|c|c|c|c|c|c|c|c|c|c|}
\hline 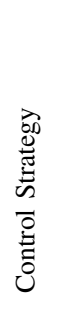 & 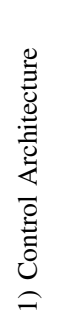 & 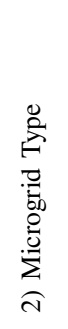 & 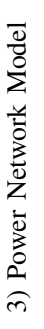 & 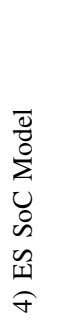 & 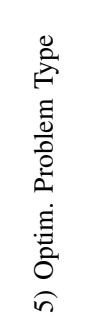 & 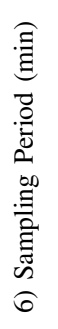 & 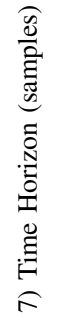 & 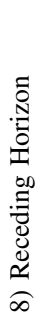 & 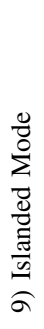 & 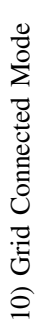 & 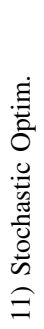 & 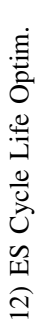 & 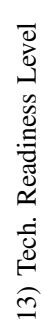 \\
\hline [78] & $\mathrm{C}$ & $\mathrm{AC}$ & $\mathrm{S}$ & $\mathrm{L}$ & $\mathrm{QP}$ & 10 & 2 & $\checkmark$ & $x$ & $\checkmark$ & $\times$ & $\times$ & \\
\hline [79] & $\mathrm{C}$ & $\mathrm{AC}$ & S & NL & DP & 10 & 144 & $x$ & $x$ & $\checkmark$ & $\times$ & $\checkmark$ & 5 \\
\hline [80] & $\mathrm{C}$ & $\mathrm{AC}$ & S & $\mathrm{L}$ & QP & 10 & 24 & $\checkmark$ & $x$ & $\checkmark$ & $x$ & $x$ & 4 \\
\hline [81] & $\mathrm{C}$ & $\mathrm{AC}$ & $\mathrm{S}$ & $\mathrm{L}$ & LP & 4 & 60 & $\checkmark$ & $\times$ & $\checkmark$ & $x$ & $\times$ & \\
\hline [82] & $\mathrm{C}$ & $\mathrm{AC}$ & $\mathrm{S}$ & PL & MILP & 60 & 24 & $\checkmark$ & $x$ & $\checkmark$ & $\times$ & $\times$ & \\
\hline [83] & $\mathrm{C}$ & $\mathrm{AC}$ & $\mathrm{S}$ & $\mathrm{L}$ & GA & 60 & 24 & $\checkmark$ & $\checkmark$ & $x$ & $x$ & $\checkmark$ & 3 \\
\hline [84] & $\mathrm{C}$ & $\mathrm{AC}$ & I & PL & MILP & 60 & 24 & $x$ & $\times$ & $\checkmark$ & $x$ & $x$ & 3 \\
\hline [85] & $\mathrm{C}$ & $\mathrm{AC}$ & I & PL & LP & 60 & 24 & $\checkmark$ & $\times$ & $\checkmark$ & $\times$ & $x$ & 2 \\
\hline [86] & $\mathrm{C}$ & $\mathrm{AC}$ & I & PL & MIQP & 10 & 18 & $\checkmark$ & $\times$ & $\checkmark$ & $\times$ & $\checkmark$ & $J$ \\
\hline [87] & $\mathrm{C}$ & $\mathrm{AC}$ & I & $\mathrm{NL}$ & DP & 60 & 24 & $x$ & $x$ & $\checkmark$ & $\checkmark$ & $\checkmark$ & 3 \\
\hline [88] & $\mathrm{C}$ & $\mathrm{AC}$ & I & PL & PSO & 5 & 12 & $\checkmark$ & $x$ & $\checkmark$ & $x$ & $x$ & 5 \\
\hline [89] & $\mathrm{C}$ & $\mathrm{AC}$ & I & PL & PSO & 5 & 12 & $\checkmark$ & $\times$ & $\checkmark$ & $\times$ & $\times$ & 5 \\
\hline [91] & $\mathrm{C}$ & $\mathrm{AC}$ & $\mathrm{C}$ & $\mathrm{L}$ & $\mathrm{QP}$ & 60 & 24 & $\checkmark$ & $\checkmark$ & $\times$ & $\times$ & $\times$ & 2 \\
\hline [92] & $\mathrm{C}$ & $\mathrm{AC}$ & $\mathrm{C}$ & PL & QP & 60 & 24 & $\checkmark$ & $\checkmark$ & $x$ & $x$ & $x$ & 3 \\
\hline [93] & $\mathrm{C}$ & $\mathrm{AC}$ & $\mathrm{C}$ & $\mathrm{L}$ & SDP & 60 & 24 & $x$ & $\checkmark$ & $\times$ & $\times$ & $x$ & 3 \\
\hline [95] & $\mathrm{C}$ & $\mathrm{AC}$ & $\mathrm{N}$ & PL & MNLP & 5 & 24 & $\checkmark$ & $\checkmark$ & $x$ & $x$ & $x$ & 4 \\
\hline [96] & $\mathrm{C}$ & $\mathrm{AC}$ & $\mathrm{N}$ & PL & MNLP & 5 & 24 & $\checkmark$ & $\checkmark$ & $\times$ & $\checkmark$ & $\times$ & 4 \\
\hline [12] & $\mathrm{C}$ & $\mathrm{AC}$ & $\mathrm{N}$ & PL & DP & 6 & 720 & $x$ & $\times$ & $\checkmark$ & $\times$ & $\times$ & 3 \\
\hline [98] & $\mathrm{C}$ & Hyb & $\mathrm{S}$ & NL & MNLP & 60 & 24 & $x$ & $x$ & $\checkmark$ & $x$ & $x$ & 2 \\
\hline [99] & $\mathrm{C}$ & $\mathrm{DC}$ & S & $\mathrm{L}$ & MILP & 20 & 36 & $x$ & $\checkmark$ & $\times$ & $\times$ & $\times$ & 5 \\
\hline [100] & $\mathrm{C}$ & $\mathrm{Hyb}$ & $\mathrm{S}$ & $\mathrm{L}$ & MILP & 60 & 24 & $x$ & $x$ & $\checkmark$ & $\times$ & $\checkmark$ & 2 \\
\hline [101] & $\mathrm{C}$ & $\mathrm{DC}$ & I & PL & LP & 60 & 24 & $\checkmark$ & $\times$ & $\checkmark$ & $\checkmark$ & $x$ & 3 \\
\hline [102] & $\mathrm{C}$ & $\mathrm{DC}$ & I & PL & LP & 60 & 24 & $\times$ & $\times$ & $\checkmark$ & $\times$ & $\times$ & 4 \\
\hline [103] & $\mathrm{C}$ & DC & $\mathrm{C}$ & $\mathrm{L}$ & SOCP & 240 & 6 & $x$ & $\checkmark$ & $x$ & $x$ & $\times$ & 3 \\
\hline [104] & $\mathrm{C}$ & DC & $\mathrm{C}$ & PL & $\mathrm{QP}$ & 1 & 15 & $\checkmark$ & $\checkmark$ & $\times$ & $\times$ & $\times$ & 5 \\
\hline [120] & MH & $\mathrm{AC}$ & $\mathrm{C}$ & $\mathrm{L}$ & SOCP & 60 & 24 & $\times$ & $\checkmark$ & $\checkmark$ & $\times$ & $\checkmark$ & 4 \\
\hline [121] & MH & $\mathrm{AC}$ & I & $\mathrm{L}$ & LP & 30 & 48 & $\checkmark$ & $\times$ & $\checkmark$ & $\times$ & $\times$ & 3 \\
\hline [122] & MH & $\mathrm{AC}$ & I & $\mathrm{L}$ & QP & 15 & 4 & $\checkmark$ & $\times$ & $\checkmark$ & $\times$ & $\times$ & 2 \\
\hline [123] & MT & $\mathrm{AC}$ & $\mathrm{C}$ & $\mathrm{L}$ & QP & 15 & 96 & $x$ & $\checkmark$ & $\times$ & $\times$ & $\times$ & 3 \\
\hline [124] & MT & $\mathrm{AC}$ & $\mathrm{C}$ & $\mathrm{L}$ & QP & 60 & 5 & $x$ & $\times$ & $\checkmark$ & $\times$ & $\times$ & 3 \\
\hline [125] & MT & $\mathrm{AC}$ & I & $\mathrm{L}$ & QP & 60 & 50 & $x$ & $\times$ & $\checkmark$ & $\times$ & $\times$ & 3 \\
\hline [126] & MF & $\mathrm{AC}$ & I & $\mathrm{L}$ & QP & 5 & 20 & $\checkmark$ & $\checkmark$ & $x$ & $x$ & $x$ & 4 \\
\hline [127] & MF & $\mathrm{AC}$ & $\mathrm{C}$ & $\mathrm{L}$ & QP & 5 & 3 & $\checkmark$ & $\checkmark$ & $\times$ & $\times$ & $x$ & 5 \\
\hline
\end{tabular}

(i.e. no charge/discharge losses).

5) Optimisation Problem Type: (MILP) Mixed integer linear programming, (MIQP) mixed integer quadratic programming, (MNLP) combined mixed integer linear and nonlinear programming, (GA) genetic algorithm, (PSO) particle swarm optimisation, (DP) dynamic programming, (SDP) semidefinite programming, (SOCP) second-order cone programming, (QP) quadratic programming or (LP) linear programming.

6) Sampling Period (minutes)

7) Time Horizon (samples): The number of sampling intervals over which the microgrid load and generation are predicted, and the optimal energy flows calculated. 
8) Receding Horizon: $(\checkmark)$ The DOPF strategy is implemented using receding horizon MPC for real-time microgrid control or $(\times)$ the optimisation is performed offline (e.g. for day-ahead scheduling).

9) Islanded Mode: $(\checkmark)$ or $(\times)$.

10) Grid Connected Mode: $(\checkmark)$ or $(\times)$.

11) Stochastic Optimisation: $(\checkmark)$ or $(\times)$.

12) ES Cycle Life Optimised: $(\checkmark)$ or $(\times)$.

13) Technology Readiness Level: (1) - (9).

Technology readiness levels are a standard means of assessing the maturity of a technology [131]. Descriptions specific to the renewable energy sector are provided in [132]. The control strategies for distributed microgrid ES systems range from level 2 to level 5, indicating the emerging nature of this research area. Technology readiness level 6 requires a successful demonstration in a relevant end-to-end environment, and has not yet been achieved.

\section{Future Research: From Autonomous Agents TO INTELLIGENT AGENTS}

Integrating distributed renewable generation sources and ES systems into power networks, and organising them into autonomous microgrids, can increase network reliability, flexibility and scalability [1]. A distributed multi-agent control strategy is a natural extension of this transition, utilising localised processing and communications infrastructure to extend the benefits of a distributed system to the communication/control layer [22].

The move towards a smart decentralised grid is part of a broader technological movement towards systems controlled by interconnected intelligent agents [4]. Intelligent agents have been applied in a range of industries with complex network control problems, including chemical processing, manufacturing, information technology and medicine [133]. Intelligent agents (as opposed to merely autonomous agents) are defined by Wooldridge as having the following characteristics [38]:

1) Reactivity: Intelligent agents are able to perceive their environment, and respond in a timely fashion to changes that occur in it in order to satisfy their design objectives.

2) Proactiveness: Intelligent agents are able to exhibit goaldirected behaviour by taking initiative in order to satisfy their design objectives.

3) Social Ability: Intelligent agents are capable of interacting with other agents (and possibly humans) in order to satisfy their design objectives.

Social ability distinguishes a system controlled by distributed intelligent agents from a system controlled by a centralised or decentralised strategy. The multi-agent control strategies presented in Section $\mathrm{V}$ use interconnected autonomous agents, providing increased robustness, scalability and flexibility over centralised control strategies. However, these strategies lack the full range of characteristics desired from intelligent agents. In particular:

- The agents are designed for a particular microgrid, with limited ability to react to different operating environments.

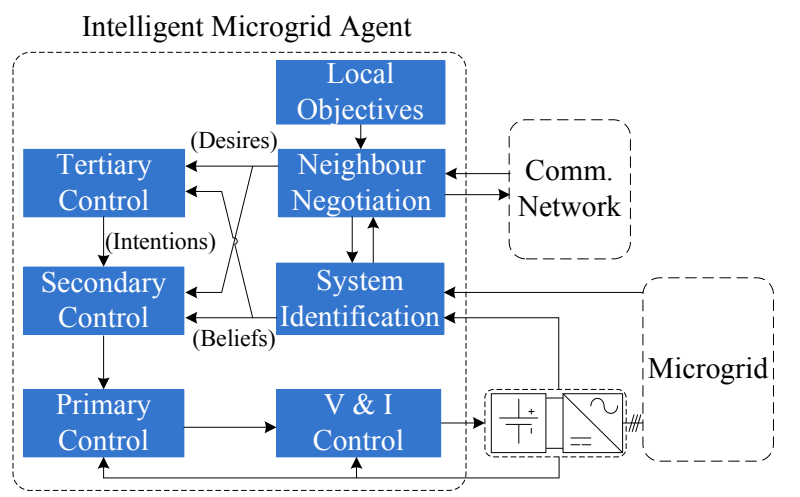

Fig. 5. A block diagram of an intelligent microgrid agent within the proposed framework, controlling a battery ES system. The power network information available to the agent, including state estimates and predictions, are described as its beliefs. The agent's desires are its objectives and operating constraints. The agent's intentions are the references for the lower control levels, generated by its tertiary level control strategy.

- The agents plan their actions using a given tertiary level strategy, rather than proactively adjusting they strategy based on the power network information, processing infrastructure and communications infrastructure available to them.

- The agents operate based on predefined neighbour-toneighbour feedback loops, or compete in a market, without the ability to negotiate based on shared objectives.

A high-level framework is proposed for the control of microgrids with distributed ES systems, based on a network of intelligent agents. The aim of the framework is to provide a research path towards the development of a generally applicable control strategy for microgrids making up the future smart decentralised grid.

Fig. 5 shows a block diagram for an intelligent microgrid agent within the proposed framework. It is assumed that each agent has a set of sensors providing limited observability of the power network and controls a set of sources, ES systems and/or loads. The primary, secondary and tertiary control blocks are maintained, as well as the low-level converter control. Additional blocks are added for system identification and neighbour negotiation.

The proposed framework is based on the procedural reasoning system for implementing belief-desire-intention model intelligent agents within dynamic environments [134]. In this model, the power network information available to an agent, including state estimates and predictions, are described as its beliefs. The agent's desires are its objectives and operating constraints. The agent's intentions are the references for the lower control levels, generated by its tertiary level control strategy.

The system identification block embodies the ability of the intelligent agent to update its beliefs. This provides the first requirement for reactivity, i.e. the ability of the agent to perceive its environment. Future microgrid applications are expected to include varying power network and communication network topologies, sources and loads connecting/disconnecting from the network and ES systems with varying characteristics 
due to operating conditions and lifetime degradation. System identification is required for real-time ES system SoC and lifetime estimation, renewable generation and load prediction and power network identification. System identification has been recognised as a key functionality for developing an intelligent microgrid energy management system (i.e. an intelligent tertiary level DOPF strategy) [135]. A desirable extension, facilitated by interconnected intelligent agents, would be a distributed implementation for microgrid system identification, using local sensors and sparse communications, and without data centralisation, which could introduce privacy concerns.

Social ability is provided by the neighbour negotiation block. The existing distributed multi-agent microgrid control strategies are based on either predefined neighbour-toneighbour feedback loops between the agents, or competition in a market. Intelligent agents use request based communication, rather than being directly controlled by their neighbours. This allows the agents to balance their desire to be cooperative against local objectives and constraints, which may not be known by their neighbours, or may be in competition with their neighbours' objectives. In particular, small distributed ES systems need to act collectively to provide substantial energy shifting, peak shaving, power quality regulation and spinning reserve to the main grid. If these services are appropriately compensated, owners of small distributed ES systems may be better off cooperating, and sharing the profits generated, rather than competing individually. Neighbour-to-neighbour negotiation provides a scalable means of achieving this.

Social ability also implies a fully distributed communication architecture, as shown in Fig. 4(c) (instead of a hierarchical or topology based message passing architecture), since the agents should make use of the available communication paths between them, rather than operating within fixed roles and interrelations.

The tertiary control level is responsible for generating the agent's intentions. Proactiveness implies that this incorporates the agent's desires and beliefs. Tertiary level DOPF strategies based on MPC partially fulfil this, generating optimal power references using up to date ES system SoC estimates and renewable generation and load predictions. However, the distributed multi-agent tertiary level DOPF strategies reviewed in Section V-B vary significantly in terms of the approximations applied to the problem, the information required by each agent and the communication architecture between them. A proactive agent should adapt its tertiary level strategy to make the best use of its available information, communications and processing infrastructure.

The secondary and primary control levels provide the second requirement of reactivity, i.e. adjusting the agent's intended actions to respond in a timely fashion to changes in its environment. The secondary control level operates between sampling intervals of the tertiary control strategy, and adjusts the agent's intended actions in response to disturbances (e.g. power network faults, prediction errors, communication failures) considering the agent's constraints and the characteristics of the devices it controls. Also, multi-agent SoC balancing on the secondary control level could be used to aggregate ES systems, simplifying the tertiary level DOPF problem. A decentralised primary load sharing strategy is maintained, so that the stability of the microgrid is not dependent on the communication network and higher level control functions.

\section{CONCLUSION}

This paper has presented an overview of the state of the art control strategies for microgrids with distributed ES systems. The introduction of distributed ES systems has been identified as a fundamental change for power networks, introducing significant opportunities if scalable, flexible and robust control strategies can be developed to fully utilise their potential. The latest technical literature on decentralised and centralised control strategies has been reviewed, as well as recent work on distributed multi-agent control strategies, which offer a desirable middle ground between the two extremes. A technology readiness level assessment of the control strategies has also been presented. The next step towards industry translation is a successful demonstration in a relevant end-to-end environment. Finally, a framework for multi-agent microgrid control, based on interconnected intelligent agents, has been proposed. This provides a promising direction for future research towards a generally applicable control strategy suitable for microgrids making up the future smart decentralised grid.

\section{REFERENCES}

[1] A. Ipakchi and F. Albuyeh, "Grid of the future," IEEE Power and Energy Magazine, vol. 7, no. 2, pp. 52-62, Mar. 2009.

[2] J. M. Carrasco, L. G. Franquelo, J. T. Bialasiewicz, E. Galván, R. C. P. Guisado, M. Ángeles, M. Prats, J. I. León, and N. Moreno-alfonso, "Power-Electronic Systems for the Grid Integration of Renewable Energy Sources : A Survey," vol. 53, no. 4, pp. 1002-1016, Aug. 2006.

[3] M. S. Whittingham, "History, Evolution, and Future Status of Energy Storage," Proceedings of the IEEE, vol. 100, no. Special Centennial Issue, pp. 1518-1534, May 2012.

[4] D. J. Hill, T. Liu, and G. Verbic, "Smart grids as distributed learning control," in 2012 IEEE Power and Energy Society General Meeting, July 2012, pp. 1-8.

[5] X. Yu and Y. Xue, "Smart Grids : A Cyber-Physical Systems Perspective," Proceedings of the IEEE, vol. 104, no. 5, May 2016.

[6] J. J. Justo, F. Mwasilu, J. Lee, and J.-W. Jung, "AC-microgrids versus DC-microgrids with distributed energy resources: A review," Renewable and Sustainable Energy Reviews, vol. 24, pp. 387-405, Aug. 2013.

[7] R. H. Lasseter, "MicroGrids," in 2002 IEEE Power Engineering Society Winter Meeting. Conference Proceedings (Cat. No.02CH37309), vol. 1, 2002, pp. 305-308.

[8] S. Parhizi, H. Lotfi, A. Khodaei, and S. Bahramirad, "State of the Art in Research on Microgrids: A Review," IEEE Access, vol. 3, pp. 890-925, June 2015.

[9] J. M. Guerrero, J. C. Vásquez, J. Matas, L. G. de Vicuna, and M. Castilla, "Hierarchical Control of Droop-Controlled AC and DC Microgrids - A General Approach Toward Standardization," IEEE Transactions on Industrial Electronics, vol. 58, no. 1, pp. 158-172, Jan. 2011.

[10] A. Bidram and A. Davoudi, "Hierarchical Structure of Microgrids Control System," IEEE Transactions on Smart Grid, vol. 3, no. 4, pp. 1963-1976, Dec. 2012.

[11] J. M. Guerrero, L. G. de Vicuna, J. Matas, M. Castilla, and J. Miret, "A Wireless Controller to Enhance Dynamic Performance of Parallel Inverters in Distributed Generation Systems," IEEE Transactions on Power Electronics, vol. 19, no. 5, pp. 1205-1213, Sept. 2004.

[12] Y. Levron, J. M. Guerrero, and Y. Beck, "Optimal Power Flow in Microgrids With Energy Storage," IEEE Transactions on Power Systems, vol. 28, no. 3, pp. 3226-3234, Aug. 2013.

[13] D. E. Olivares, A. Mehrizi-Sani, A. H. Etemadi, C. A. Cañizares, R. Iravani, M. Kazerani, A. H. Hajimiragha, O. Gomis-Bellmunt, M. Saeedifard, R. Palma-Behnke, G. A. Jimenez-Estevez, and N. D. Hatziargyriou, "Trends in Microgrid Control," IEEE Transactions on Smart Grid, vol. 5, no. 4, pp. 1905-1919, July 2014. 
[14] C. Restrepo, A. Salazar, H. Schweizer, and A. Ginart, "Residential Battery Storage: Is the Timing Right?" IEEE Electrification Magazine, vol. 3, no. 3, pp. 14-21, Sept. 2015.

[15] Z. Yang, C. Shen, L. Zhang, M. L. Crow, and S. Atcitty, "Integration of a StatCom and battery energy storage," IEEE Transactions on Power Systems, vol. 16, no. 2, pp. 254-260, May 2001.

[16] V. Kontorinis, L. E. Zhang, B. Aksanli, J. Sampson, H. Homayoun, E. Pettis, D. M. Tullsen, and T. S. Rosing, "Managing distributed UPS energy for effective power capping in data centers," in Computer Architecture (ISCA), 2012 39th Annual International Symposium on, June 2012, pp. 488-499.

[17] D. Wang, C. Ren, A. Sivasubramaniam, B. Urgaonkar, and H. Fathy, "Energy storage in datacenters: what, where and how much?" $A C M$ SIGMETRICS Performance Evaluation Review, vol. 40, no. 1, p. 187, June 2012.

[18] T. Morstyn, B. Hredzak, and V. G. Agelidis, "Distributed Cooperative Control of Microgrid Storage," IEEE Transactions on Power Systems, vol. 30, no. 5, pp. 2780-2789, Oct. 2014.

[19] E. R. Sanseverino, M. L. Di Silvestre, N. N. Quang, L. Mineo, J. M. Guerrero, A. C. Luna, J. C. Vásquez, and M. Graells, "Energy Management Systems and tertiary regulation in hierarchical control architectures for islanded microgrids," in 2015 IEEE 15th International Conference on Environment and Electrical Engineering (EEEIC), June 2015, pp. 144-149.

[20] D. Lim and A. Anbuky, "A Distributed Industrial Battery Management Network," IEEE Transactions on Industrial Electronics, vol. 51, no. 6, pp. 1181-1193, Dec. 2004

[21] Y. Simmhan, A. G. Kumbhare, B. Cao, and V. Prasanna, "An Analysis of Security and Privacy Issues in Smart Grid Software Architectures on Clouds," in 2011 IEEE 4th International Conference on Cloud Computing, July 2011, pp. 582-589.

[22] S. D. J. McArthur, E. M. Davidson, V. M. Catterson, A. L. Dimeas, N. D. Hatziargyriou, F. Ponci, and T. Funabashi, "Multi-Agent Systems for Power Engineering Applications - Part I: Concepts, Approaches, and Technical Challenges," IEEE Transactions on Power Systems, vol. 22, no. 4, pp. 1743-1752, Nov. 2007.

[23] F. L. Lewis, H. Zhang, K. Hengster-Movric, and A. Das, Cooperative Control of Multi-Agent Systems, ser. Communications and Control Engineering. London: Springer London, 2014.

[24] A. Bidram, A. Davoudi, F. L. Lewis, and J. M. Guerrero, "Distributed Cooperative Secondary Control of Microgrids Using Feedback Linearization," IEEE Transactions on Power Systems, vol. 28, no. 3, pp. 3462-3470, Aug. 2013.

[25] J. W. Simpson-Porco, F. Dörfler, and F. Bullo, "Synchronization and power sharing for droop-controlled inverters in islanded microgrids," Automatica, vol. 49, no. 9, pp. 2603-2611, Sept. 2013.

[26] Q. Shafiee, J. M. Guerrero, and J. C. Vásquez, "Distributed Secondary Control for Islanded MicroGrids - A Novel Approach," IEEE Transactions on Power Electronics, vol. 29, no. 2, pp. 1018 - 1031, Apr. 2013.

[27] V. Nasirian, S. Moayedi, A. Davoudi, and F. L. Lewis, "Distributed Cooperative Control of DC Microgrids," IEEE Transactions on Power Electronics, vol. 30, no. 4, pp. 2288-2303, Apr. 2015.

[28] E. Dall'Anese, H. Zhu, and G. B. Giannakis, "Distributed Optimal Power Flow for Smart Microgrids," IEEE Transactions on Smart Grid, vol. 4, no. 3, pp. 1464-1475, Nov. 2013.

[29] S. Bolognani and S. Zampieri, "A Distributed Control Strategy for Reactive Power Compensation in Smart Microgrids," IEEE Transactions on Automatic Control, vol. 58, no. 11, pp. 2818-2833, Nov. 2013.

[30] T. Erseghe, "Distributed optimal power flow using ADMM," IEEE Transactions on Power Systems, vol. 29, no. 5, pp. 2370-2380, Sept. 2014.

[31] Q. Peng and S. H. Low, "Distributed Optimal Power Flow Algorithm for Radial Networks, I: Balanced Single Phase Case," IEEE Transactions on Smart Grid, vol. PP, pp. 1-13, Mar. 2016.

[32] F. Dörfler, J. W. Simpson-Porco, and F. Bullo, "Breaking the hierarchy: Distributed control \& economic optimality in microgrids," IEEE Transactions on Control of Network Systems, vol. PP, no. 99, July 2015.

[33] J. Zhao and F. Dörfler, "Distributed control and optimization in DC microgrids," Automatica, vol. 61, pp. 18-26, 2015.

[34] A. L. Kulasekera, R. A. R. C. Gopura, K. T. M. U. Hemapala, and N. Perera, "A Review on Multi-Agent Systems in Microgrid Applications," 2011 IEEE PES Innovative Smart Grid Technologies India, pp. 173 - 177, Dec. 2011.

[35] M. Yazdanian and A. Mehrizi-Sani, "Distributed Control Techniques in Microgrids," IEEE Transactions on Smart Grid, vol. 5, no. 6, pp. 2901-2909, Aug. 2014.
[36] A. Bidram, F. L. Lewis, and A. Davoudi, "Distributed Control Systems for Small-Scale Power Networks: Using Multiagent Cooperative Control Theory," IEEE Control Systems Magazine, vol. 34, no. 6, pp. 56-77, Nov. 2014.

[37] W. Saad, Z. Han, H. V. Poor, and T. Basar, "Game-theoretic methods for the smart grid: An overview of microgrid systems, demand-side management, and smart grid communications," IEEE Signal Processing Magazine, vol. 29, no. 5, pp. 86-105, Aug. 2012.

[38] M. Wooldridge, An Introduction to Multiagent Systems. John Wiley $\&$ Sons, 2002

[39] A. Mohd, E. Ortjohann, A. Schmelter, N. Hamsic, and D. Morton, "Challenges in integrating distributed Energy storage systems into future smart grid," in 2008 IEEE International Symposium on Industrial Electronics, June 2008, pp. 1627-1632.

[40] J. P. Barton and D. G. Infield, "Energy Storage and Its Use With Intermittent Renewable Energy," IEEE Transactions on Energy Conversion, vol. 19, no. 2, pp. 441-448, June 2004.

[41] S. Vazquez, S. M. Lukic, E. Galvan, L. G. Franquelo, and J. M. Carrasco, "Energy Storage Systems for Transport and Grid Applications," IEEE Transactions on Industrial Electronics, vol. 57, no. 12, pp. 38813895, Dec. 2010

[42] V. Agarwal, K. Uthaichana, R. A. DeCarlo, and L. H. Tsoukalas, "Development and Validation of a Battery Model Useful for Discharging and Charging Power Control and Lifetime Estimation," IEEE Transactions on Energy Conversion, vol. 25, no. 3, pp. 821-835, Sept. 2010.

[43] M. Chen and G. A. Rinc, "Accurate Electrical Battery Model Capable of Predicting Runtime and I-V Performance," vol. 21, no. 2, pp. 504511, June 2006.

[44] J. M. Guerrero, L. Hang, and J. Uceda, "Control of Distributed Uninterruptible Power Supply Systems," IEEE Transactions on Industrial Electronics, vol. 55, no. 8, pp. 2845-2859, Aug. 2008.

[45] J. Matas, M. Castilla, L. G. de Vicuna, J. Miret, and J. C. Vásquez, "Virtual Impedance Loop for Droop-Controlled Single-Phase Parallel Inverters Using a Second-Order General-Integrator Scheme," IEEE Transactions on Power Electronics, vol. 12, no. 25, pp. 2993-3002, Dec. 2010.

[46] J. M. Guerrero, J. C. Vásquez, J. Matas, M. Castilla, and L. G. de Vicuna, "Control Strategy for Flexible Microgrid Based on Parallel LineInteractive UPS Systems," IEEE Transactions on Industrial Electronics, vol. 56, no. 3, pp. 726-736, Mar. 2009.

[47] X. Lu, K. Sun, J. M. Guerrero, J. C. Vásquez, and L. Huang, "State-ofCharge Balance Using Adaptive Droop Control for Distributed Energy Storage Systems in DC Microgrid Applications," IEEE Transactions on Industrial Electronics, vol. 61, no. 6, pp. 2804-2815, June 2014.

[48] X. Lu, K. Sun, J. M. Guerrero, J. C. Vásquez, and L. Huang, "Double-Quadrant State-of-Charge-Based Droop Control Method for Distributed Energy Storage Systems in Autonomous DC Microgrids," IEEE Transactions on Smart Grid, vol. 6, no. 1, pp. 147-157, Jan. 2015.

[49] C. Gavriluta, J. I. Candela, C. Citro, J. Rocabert, A. Luna, and P. Rodríguez, "Decentralized Primary Control of MTDC Networks With Energy Storage and Distributed Generation," IEEE Transactions on Industry Applications, vol. 50, no. 6, pp. 4122-4131, Nov. 2014.

[50] R. Hu and W. W. Weaver, "Dc Microgrid Droop Control Based on Battery State of Charge Balancing," in IEEE Power and Energy Conference at Illinois (PECI), Feb. 2016, pp. 1-8.

[51] N. L. Díaz, T. Dragičević, J. C. Vásquez, and J. M. Guerrero, "FuzzyLogic-Based Gain-Scheduling Control for State-of-Charge Balance of Distributed Energy Storage Systems for DC Microgrids," in IEEE Applied Power Electronics Conference and Exposition - APEC 2014, Mar. 2014, pp. 2171-2176.

[52] N. L. Díaz, T. Dragičević, J. C. Vásquez, and J. M. Guerrero, "Intelligent Distributed Generation and Storage Units for DC Microgrids - A New Concept on Cooperative Control Without Communications Beyond Droop Control," IEEE Transactions on Smart Grid, vol. 5, no. 5, pp. 2476-2485, Sept. 2014.

[53] Y. Gu, X. Xiang, W. Li, and X. He, "Mode-Adaptive Decentralized Control for Renewable DC Microgrid With Enhanced Reliability and Flexibility," IEEE Transactions on Power Electronics, vol. 29, no. 9, pp. 5072-5080, Sept. 2014.

[54] D. Wu, F. Tang, T. Dragičević, J. C. Vásquez, and J. M. Guerrero, "A Control Architecture to Coordinate Renewable Energy Sources and Energy Storage Systems in Islanded Microgrids," IEEE Transactions on Smart Grid, vol. 6, no. 3, pp. 1156-1166, May 2015.

[55] N. L. Díaz, D. Wu, T. Dragičević, J. C. Vásquez, and J. M. Guerrero, "Stored Energy Balance for Distributed PV-Based Active Generators 
in an AC Microgrid," in 2015 IEEE Power \& Energy Society General Meeting, July 2015, pp. 1-5.

[56] N. L. Díaz, D. Wu, T. Dragičević, J. C. Vásquez, and J. M. Guerrero, "Fuzzy droop control loops adjustment for stored energy balance in distributed energy storage system," in International Conference on Power Electronics-ECCE Asia, June 2015, pp. 728-735.

[57] T. Dragičević, J. M. Guerrero, and J. C. Vásquez, "A Distributed Control Strategy for Coordination of an Autonomous LVDC Microgrid Based on Power-Line Signaling," IEEE Transactions on Industrial Electronics, vol. 61, no. 7, pp. 3313-3326, July 2014.

[58] K. Le Dinh and Y. Hayashi, "Coordinated BESS control for improving voltage stability of a PV-supplied microgrid," in 2013 48th International Universities' Power Engineering Conference (UPEC), Sept. 2013, pp. 1-6.

[59] A. Etxeberria, I. Vechiu, H. Camblong, and J. M. Vinassa, "Hybrid Energy Storage Systems for renewable Energy Sources Integration in microgrids: A review," in 2010 Conference Proceedings IPEC, Oct. 2010, pp. 532-537.

[60] Y. Gu, W. Li, and X. He, "Frequency-Coordinating Virtual Impedance for Autonomous Power Management of DC Microgrid," IEEE Transactions on Power Electronics, vol. 30, no. 4, pp. 2328-2337, 2015.

[61] M. Savaghebi, A. Jalilian, J. C. Vásquez, and J. M. Guerrero, "Secondary Control Scheme for Voltage Unbalance Compensation in an Islanded Droop-Controlled Microgrid," IEEE Transactions on Smart Grid, vol. 3, no. 2, pp. 797-807, June 2012

[62] A. Micallef, M. Apap, C. Spiteri-Staines, J. M. Guerrero, and J. C. Vásquez, "Reactive Power Sharing and Voltage Harmonic Distortion Compensation of Droop Controlled Single Phase Islanded Microgrids," IEEE Transactions on Smart Grid, vol. 5, no. 3, pp. 1149-1158, May 2014.

[63] X. Lu, K. Sun, J. Guerrero, and L. Huang, "SoC-based dynamic power sharing method with AC-bus voltage restoration for microgrid applications," IECON 2012 - 38th Annual Conference on IEEE Industrial Electronics Society, pp. 5677-5682, Oct. 2012.

[64] Y. Guan, J. M. Guerrero, and J. C. Vásquez, "Coordinated Secondary Control for Balanced Discharge Rate of Energy Storage System in Islanded Microgrids," in International Conference on Power ElectronicsECCE Asia, June 2015, pp. 475-481.

[65] H. Babazadeh, B. Asghari, and R. Sharma, "A new control scheme in a multi-battery management system for expanding microgrids," in ISGT 2014, Feb. 2014, pp. 1-5.

[66] T. Dragičević, J. M. Guerrero, J. C. Vásquez, and D. Skrlec, "Supervisory Control of an Adaptive-Droop Regulated DC Microgrid With Battery Management Capability," IEEE Transactions on Power Electronics, vol. 29, no. 2, pp. 695-706, Feb. 2014.

[67] C. Li, T. Dragičević, N. L. Díaz, J. C. Vásquez, and J. M. Guerrero, "Voltage Scheduling Droop Control for State-of-Charge Balance of Distributed Energy Storage in DC Microgrids," in Proceedings of the 2014 IEEE International Energy Conference (ENERGYCON), May 2014, pp. 1-6.

[68] H.-j. Kim, C. Y. Chun, K.-j. Lee, P. Jang, and B.-h. Cho, "Control Strategy of Multiple Energy Storages System for DC Microgrid," in International Conference on Power Electronics and ECCE Asia (ICPEECCE Asia), 2015, pp. 1750-1755.

[69] O. Palizban and K. Kauhaniemi, "Power Sharing for Distributed Energy Storage Systems in AC Microgrid : Based on State-of-Charge," in IEEE PES Asia-Pacific Power and Energy Engineering Conference (APPEEC), Nov. 2015, pp. 1-5.

[70] O. Palizban and K. Kauhaniemi, "Distributed cooperative control of battery energy storage system in AC microgrid applications," Journal of Energy Storage, vol. 3, pp. 43-51, Oct. 2015.

[71] S. Teleke, M. E. Baran, S. Bhattacharya, and A. Q. Huang, "Rule-based control of battery energy storage for dispatching intermittent renewable sources," IEEE Transactions on Sustainable Energy, vol. 1, no. 3, pp. 117-124, Oct. 2010.

[72] G. Wang, M. Ciobotaru, and V. G. Agelidis, "Power Smoothing of Large Solar PV Plant Using Hybrid Energy Storage," IEEE Transactions on Sustainable Energy, vol. 5, no. 3, pp. 834-842, July 2014

[73] G. Wang, M. Ciobotaru, and G. Vassilios, "Power Management for Improved Dispatch of Utility-Scale PV Plants," IEEE Transactions on Power Systems, vol. 31, no. 3, pp. 2297-2306, Apr. 2016.

[74] C. Wang and T. Zhang, "A Multi-Agent based Hierarchical Control System for DERs Management in Islanded Micro-Grid," in Chinese Automation Congress (CAC), 2015, Nov. 2015, pp. 1371-1376.

[75] J. A. Momoh, R. Adapa, and M. E. El-Hawary, "A review of selected optimal power flow literature to 1993. I. Nonlinear and quadratic pro- gramming approaches," IEEE Transactions on Power Systems, vol. 14, no. 1, pp. 96-104, Feb. 1999.

[76] J. Lavaei and S. H. Low, "Zero Duality Gap in Optimal Power Flow Problem," IEEE Transactions on Power Systems, vol. 27, no. 1, pp. 92-107, Feb. 2012

[77] J. B. Rawlings and D. Q. Mayne, "Model Predictive Control: Theory and Design," Madison, Wisconsin, 2009.

[78] M. Khalid and A. V. Savkin, "A model predictive control approach to the problem of wind power smoothing with controlled battery storage," Renewable Energy, vol. 35, no. 7, pp. 1520-1526, July 2010.

[79] Y. Riffonneau, S. Bacha, F. Barruel, and S. Ploix, "Optimal Power Flow Management for Grid Connected PV Systems With Batteries," IEEE Transactions on Sustainable Energy, vol. 2, no. 3, pp. 309-320, 2011.

[80] E. Mayhorn, K. Kalsi, M. Elizondo, N. Samaan, and K. Butler-Purry, "Optimal control of distributed energy resources using model predictive control," in 2012 IEEE Power and Energy Society General Meeting, July 2012 , pp. 1-8.

[81] E. Perez, H. Beltran, N. Aparicio, and P. Rodriguez, "Predictive Power Control for PV Plants With Energy Storage," IEEE Transactions on Sustainable Energy, vol. 4, no. 2, pp. 482-490, Apr. 2013.

[82] A. Parisio, E. Rikos, and L. Glielmo, "A Model Predictive Control Approach to Microgrid Operation Optimization," IEEE Transactions on Control Systems Technology, vol. 22, no. 5, pp. 1813-1827, Sept. 2014.

[83] B. Zhao, X. Zhang, J. Chen, C. Wang, and L. Guo, "Operation optimization of standalone microgrids considering lifetime characteristics of battery energy storage system," IEEE Transactions on Sustainable Energy, vol. 4, no. 4, pp. 934-943, 2013.

[84] P. Gburczyk, I. Wasiak, R. Mienski, and R. Pawelek, "Energy management system as a mean for the integration of distributed energy sources with low voltage network," in International Conference on Electrical Power Quality and Utilisation (EPQU), Oct. 2011, pp. 1-5.

[85] H. Dagdougui, L. Dessaint, and A. Ouammi, "Optimal power exchanges in an interconnected power microgrids based on model predictive control," 2014 IEEE PES General Meeting - Conference \& Exposition, pp. 1-5, July 2014.

[86] F. Garcia-Torres and C. Bordons, "Optimal Economical Schedule of Hydrogen-Based Microgrids With Hybrid Storage Using Model Predictive Control," IEEE Transactions on Industrial Electronics, vol. 62, no. 8, pp. 5195-5207, Aug. 2015.

[87] T. A. Nguyen and M. L. Crow, "Stochastic Optimization of RenewableBased Microgrid Operation Incorporating Battery Operating Cost," IEEE Transactions on Power Systems, vol. PP, no. 99, pp. 1-8, 2015.

[88] Z. Bao, Q. Zhou, Z. Yang, Q. Yang, L. Xu, and T. Wu, "A Multi Time-Scale and Multi Energy-Type Coordinated Microgrid Scheduling Solution - Part I: Optimization Algorithm and Case Studies," IEEE Transactions on Power Systems, vol. 30, no. 5, pp. 2257-2266, Sept. 2015.

[89] Z. Bao, Q. Zhou, Z. Yang, Q. Yang, L. Xu, and T. Wu, "A Multi Time-Scale and Multi Energy-Type Coordinated Microgrid Scheduling Solution - Part II: Optimization Algorithm and Case Studies," IEEE Transactions on Power Systems, vol. 30, no. 5, pp. 2267-2277, Sept. 2015.

[90] S. Boyd and L. Vandenberghe, Convex Optimization. Cambridge University Press, 2004.

[91] K. M. Chandy, S. H. Low, U. Topcu, and H. Xu, "A Simple Optimal Power Flow Model with Energy Storage," in 49th IEEE Conference on Decision and Control (CDC), Dec. 2010, pp. $1051-1057$.

[92] P. P. Zeng, Z. Wu, X.-P. Zhang, C. Liang, and Y. Zhang, "Model predictive control for energy storage systems in a network with high penetration of renewable energy and limited export capacity," 2014 Power Systems Computation Conference, pp. 1-7, Aug. 2014.

[93] D. Gayme and U. Topcu, "Optimal power flow with large-scale storage integration," IEEE Transactions on Power Systems, vol. 28, no. 2, pp. 709-717, May 2013.

[94] M. Farivar and S. H. Low, "Branch Flow Model: Relaxations and Convexification (Part I)," IEEE Transactions on Power Systems, vol. 28, no. 3, pp. 2554-2564, Apr. 2013.

[95] D. E. Olivares, C. A. Cañizares, and M. Kazerani, "A Centralized Energy Management System for Isolated Microgrids," IEEE Transactions on Smart Grid, vol. 5, no. 4, pp. 1864-1875, July 2014.

[96] D. E. Olivares, J. D. Lara, C. A. Cañizares, and M. Kazerani, "Stochastic-Predictive Energy Management System for Isolated Microgrids," IEEE Transactions on Smart Grid, vol. 6, no. 6, pp. 2681-2693, Nov. 2015. 
[97] T. M. Haileselassie and K. Uhlen, "Impact of DC Line Voltage Drops on Power Flow of MTDC Using Droop Control," IEEE Transactions on Power Systems, vol. 27, no. 3, pp. 1441-1449, Aug. 2012.

[98] N. Qachchachi, H. Mahmoudi, and A. El Hasnaoui, "Optimal power flow for a hybrid AC/DC microgrid," in 2014 International Renewable and Sustainable Energy Conference (IRSEC), vol. 6, no. 3, Oct. 2014, pp. 559-564.

[99] M. Sechilariu, B. Wang, and F. Locment, "Power management and optimization for isolated DC microgrid," International Symposium on Power Electronics, Electrical Drives, Automation and Motion (SPEEDAM), pp. 1284-1289, 2014.

[100] P. Teimourzadeh Baboli, S. Bahramara, M. Parsa Moghaddam, and M.R. Haghifam, "A Mixed-Integer Linear Model for Optimal Operation of Hybrid AC-DC Microgrid Considering Renewable Energy Resources and PHEVs," in 2015 IEEE Eindhoven PowerTech, June 2015, pp. 1-5.

[101] M. Gulin, J. Matusko, and M. Vasak, "Stochastic model predictive control for optimal economic operation of a residential DC microgrid," in 2015 IEEE International Conference on Industrial Technology (ICIT), Mar. 2015, pp. 505-510.

[102] K. Strunz, E. Abbasi, and D. N. Huu, "DC Microgrid for Wind and Solar Power Integration," IEEE Journal of Emerging and Selected Topics in Power Electronics, vol. 2, no. 1, pp. 115-126, Mar. 2014.

[103] X. Lou and C. W. Tan, "Convex relaxation and decomposition in large resistive power networks with energy storage," in 2013 IEEE International Conference on Smart Grid Communications (SmartGridComm), Oct. 2013, pp. 642-647.

[104] T. Morstyn, B. Hredzak, and V. G. Agelidis, "Dynamic Optimal Power Flow for DC Microgrids with Distributed Battery Energy Storage Systems," in 2016 IEEE Energy Conversion Congress and Exposition $(E C C E)$. (In Press).

[105] J. A. Fax and R. M. Murray, "Information Flow and Cooperative Control of Vehicle Formations," IEEE Transactions on Automatic Control, vol. 49, no. 9, pp. 1465-1476, Sept. 2004.

[106] R. Olfati-Saber and R. M. Murray, "Consensus Problems in Networks of Agents With Switching Topology and Time-Delays," IEEE Transactions on Automatic Control, vol. 49, no. 9, pp. 1520-1533, Sept. 2004.

[107] R. Olfati-Saber, J. A. Fax, and R. M. Murray, "Consensus and Cooperation in Networked Multi-Agent Systems," Proceedings of the IEEE, vol. $95,2007$.

[108] F. L. Lewis and A. Das, "Optimal Design for Synchronization of Cooperative Systems: State Feedback, Observer and Output Feedback," IEEE Transactions on Automatic Control, vol. 56, no. 8, pp. 19481952, Aug. 2011.

[109] A. Popov and H. Werner, "Robust Stability of a Multi-Agent System Under Arbitrary and Time-Varying Communication Topologies and Communication Delays," IEEE Transactions on Automatic Control, vol. 57, no. 9, pp. 2343-2347, Sept. 2012.

[110] P. Wieland, R. Sepulchre, and F. Allgöwer, "An internal model principle is necessary and sufficient for linear output synchronization," Automatica, vol. 47, no. 5, pp. 1068-1074, May 2011 .

[111] C. Li, T. Dragičević, J. C. Vásquez, J. M. Guerrero, and E. A. A. Coelho, "Multi-agent-based distributed state of charge balancing control for distributed energy storage units in AC microgrids," in 2015 IEEE Applied Power Electronics Conference and Exposition (APEC), Mar. 2015, pp. 2967-2973.

[112] T. Morstyn, B. Hredzak, and V. G. Agelidis, "Communication delay robustness for multi-agent state of charge balancing between distributed AC microgrid storage systems," in 2015 IEEE Conference on Control Applications (CCA), Sept. 2015, pp. 181-186.

[113] T. Morstyn, B. Hredzak, V. G. Agelidis, and G. Demetriades, "Cooperative control of DC microgrid storage for energy balancing and equal power sharing," in 2014 Australasian Universities Power Engineering Conference (AUPEC), Sept. 2014, pp. 1-6.

[114] C. Li, T. Dragičević, M. G. Plaza, F. Andrade, J. C. Vásquez, and J. M. Guerrero, "Multiagent based distributed control for state-of-charge balance of distributed energy storage in DC microgrids," in IECON 2014 - 40th Annual Conference of the IEEE Industrial Electronics Society, Oct. 2014, pp. 2180-2184

[115] T. Morstyn, B. Hredzak, G. D. Demetriades, and V. G. Agelidis, "Unified Distributed Control for DC Microgrid Operating Modes," IEEE Transactions on Power Systems, vol. 31, no. 1, pp. 802-812, Mar. 2015.

[116] T. Morstyn, B. Hredzak, and V. G. Agelidis, "Cooperative MultiAgent Control of Heterogeneous Storage Devices Distributed in a DC Microgrid," IEEE Transactions on Power Systems, vol. 31, no. 4, pp. 2974-2986, Sept. 2015.
[117] C. P. Nguyen and A. Flueck, "Agent Based Restoration With Distributed Energy Storage Support in Smart Grids," IEEE Transactions on Smart Grid, vol. 3, no. 2, pp. 1029-1038, June 2012.

[118] Y. Xu, W. Zhang, G. Hug, S. Kar, and Z. Li, "Cooperative Control of Distributed Energy Storage Systems in a Microgrid," IEEE Transactions on Smart Grid, vol. 6, no. 1, pp. 238-248, Jan. 2015.

[119] J. M. Maestre and R. R. Negenborn, Distributed Model Predictive Control Made Easy. Springer Publishing Company, Incorporated, 2013.

[120] W. Shi, X. Xie, C.-c. Chu, and R. Gadh, "A distributed optimal energy management strategy for microgrids," in 2014 IEEE International Conference on Smart Grid Communications (SmartGridComm), vol. 6, no. 3, Nov. 2014, pp. 200-205.

[121] K. Worthmann, C. M. Kellett, P. Braun, L. Grüne, and S. R. Weller, "Distributed and Decentralized Control of Residential Energy Systems Incorporating Battery Storage," IEEE Transactions on Smart Grid, vol. 6, no. 4, pp. 1914-1923, July 2015.

[122] R. Minciardi, M. Robba, F. Delfino, and F. Pampararo, "A Multilevel Approach for the Optimal Control of Energy Systems Distributed over the Territory," in 2013 European Modelling Symposium, Nov. 2013, pp. $414-419$.

[123] M. Kraning, E. Chu, J. Lavaei, and S. Boyd, "Dynamic Network Energy Management via Proximal Message Passing," Foundations and Trends in Optimization, vol. 1, no. 2, pp. 70-122, Nov. 2014.

[124] A. Cortés and S. Martínez, "On distributed reactive power and storage control on microgrids," International Journal of Robust and Nonlinear Control, Jan. 2016.

[125] H. Dagdougui and R. Sacile, "Decentralized Control of the Power Flows in a Network of Smart Microgrids Modeled as a Team of Cooperative Agents," IEEE Transactions on Control Systems Technology, vol. 22, no. 2, pp. 510-519, Mar. 2014.

[126] G. Hug, S. Kar, and C. Wu, "Consensus+Innovations Approach for Distributed Multiagent Coordination in a Microgrid," IEEE Transactions on Smart Grid, vol. 6, no. 4, pp. 1893-1903, Apr. 2015.

[127] T. Morstyn, B. Hredzak, and V. G. Agelidis, "Network Topology Independent Multi-Agent Dynamic Optimal Power Flow for Microgrids with Distributed Energy Storage Systems," IEEE Transactions on Smart Grid, vol. PP, pp. 1-11, Nov. 2016.

[128] I. Maity and S. Rao, "Simulation and pricing mechanism analysis of a solar-powered electrical microgrid," IEEE Systems Journal, vol. 4, no. 3, pp. 275-284, Sept. 2010.

[129] M. H. Cintuglu, H. Martin, and O. A. Mohammed, "Real-time implementation of multiagent-based game theory reverse auction model for microgrid market operation," IEEE Transactions on Smart Grid, vol. 6, no. 2, pp. 1064-1072, Mar. 2015.

[130] A. Mondal, S. Misra, and M. S. Obaidat, "Distributed Home Energy Management System With Storage in Smart Grid Using Game Theory," IEEE Systems Journal, vol. PP, May 2015.

[131] J. C. Mankins, "Technology readiness levels," Office of Space Access and Technology, NASA, 1995.

[132] "Technology Readiness Levels for Renewable Energy Sectors," Australian Renewable Energy Agency (ARENA), 2014.

[133] N. R. Jennings and M. Wooldridge, "Agent technology." SpringerVerlag New York, Inc., 1998, ch. Applications of Intelligent Agents, pp. 3-28.

[134] M. P. Georgeff and A. Lansky, "Reactive Reasoning and Planning," in Proceedings of the Sixth National Conference on Artificial Intelligence, 1987, pp. 677-682.

[135] W. Su and J. Wang, "Energy Management Systems in Microgrid Operations," The Electricity Journal, vol. 25, no. 8, pp. 45-60, Oct. 2012.

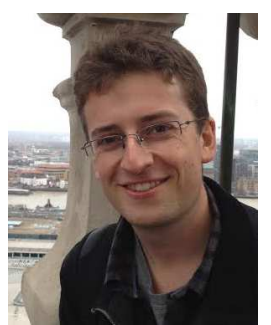

Thomas Morstyn (S'13) received the B.E. (Hon.) degree in electrical engineering from the University of Melbourne, Australia, in 2011.

He worked as an electrical engineer in the Rio Tinto Technology and Innovation group for two years. He is currently working towards the Ph.D. degree at the Australian Energy Research Institute, The University of New South Wales, Sydney, NSW, Australia. His research interests include multi-agent control and optimisation for the integration of distributed renewable generation and energy storage systems into power networks. 


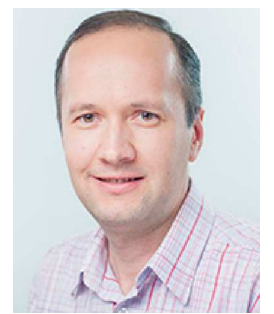

Branislav Hredzak (M'98-SM'13) received the B.Sc./M.Sc. degree from the Technical University of Kosice, Slovak Republic, in 1993, and the Ph.D. degree from Napier University of Edinburgh, U.K., in 1997, all in electrical engineering.

He was a Lecturer and a Senior Researcher in Singapore from 1997 to 2007 . He is currently a Senior Lecturer in the School of Electrical Engineering and Telecommunications, The University of New South Wales, Sydney, NSW, Australia. His current research interests include hybrid storage technologies and advanced control systems for power electronics and storage systems.

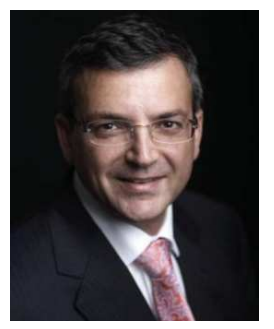

Vassilios G. Agelidis (S'89-M'91-SM'00-F'16) was born in Serres, Greece. He received the B.Eng. degree in electrical engineering from the Democritus University of Thrace, Thrace, Greece, in 1988, the M.S. degree in applied science from Concordia University, Montreal, QC, Canada, in 1992, and the $\mathrm{Ph} . \mathrm{D}$. degree in electrical engineering from Curtin University, Perth, Australia, in 1997. He has worked at Curtin University (1993-1999), University of Glasgow, U.K. (2000-2004), Murdoch University, Perth, Australia (2005-2006), the University of Sydney, Australia (2007-2010), and the University of New South Wales (UNSW), Sydney, Australia (2010-2016). He is currently a professor at the Department of Electrical Engineering, Technical University of Denmark.

Dr. Agelidis received the Advanced Research Fellowship from the U.K.'s Engineering and Physical Sciences Research Council in 2004. He was the Vice-President Operations within the IEEE Power Electronics Society from 2006 to 2007. He was an AdCom Member of the IEEE Power Electronics Society from 2007 to 2009 and the Technical Chair of the 39th IEEE Power Electronics Specialists Conference, Rhodes, Greece, 2008. 